\title{
Review \\ A Review of Optical Fibre Ethanol Sensors: Current State and Future Prospects
}

\author{
Sanober Farheen Memon 1,2,*(-), Ruoning Wang ${ }^{1,3}$, Bob Strunz $^{2}$, Bhawani Shankar Chowdhry ${ }^{4}$, \\ J. Tony Pembroke ${ }^{5(1)}$ and Elfed Lewis $1,2, *$ (B)
}

1 Optical Fibre Sensors Research Centre, University of Limerick, V94 T9PX Limerick, Ireland; ruonwang@hrbeu.edu.cn

2 Department of Electronic and Computer Engineering, University of Limerick, V94 T9PX Limerick, Ireland ; Bob.Strunz@ul.ie

3 Key Laboratory of In-Fiber Integrated Optics of Ministry of Education, College of Physics and Optoelectronic Engineering, Harbin Engineering University, Harbin 150001, China

4 NCRA-CMS Lab, IICT, Mehran University of Engineering and Technology, Jamshoro 76062, Sindh, Pakistan; bhawani.chowdhry@faculty.muet.edu.pk

5 Department of Chemical Sciences and Bernal Institute, University of Limerick, V94 T9PX Limerick, Ireland; Tony.Pembroke@ul.ie

* Correspondence: Sanober.Farheen@ul.ie (S.F.M.); Elfed.Lewis@ul.ie (E.L.)

Citation: Memon, S.F.; Wang, R.; Strunz, B.; Chowdhry, B.S.; Pembroke, J.T.; Lewis, E. A Review of Optical Fibre Ethanol Sensors: Current State and Future Prospects. Sensors 2022, 22,950. https://doi.org/10.3390/ s22030950

Academic Editor: Roberto Pizzoferrato

Received: 10 December 2021

Accepted: 21 January 2022

Published: 26 January 2022

Publisher's Note: MDPI stays neutral with regard to jurisdictional claims in published maps and institutional affiliations.

Copyright: (C) 2022 by the authors. Licensee MDPI, Basel, Switzerland. This article is an open access article distributed under the terms and conditions of the Creative Commons Attribution (CC BY) license (https:// creativecommons.org/licenses/by/ $4.0 /)$.

\begin{abstract}
A range of optical fibre-based sensors for the measurement of ethanol, primarily in aqueous solution, have been developed and are reviewed here. The sensing approaches can be classified into four groups according to the measurement techniques used, namely absorption (or absorbance), external interferometric, internal fibre grating and plasmonic sensing. The sensors within these groupings can be compared in terms of their characteristic performance indicators, which include sensitivity, resolution and measurement range. Here, particular attention is paid to the potential application areas of these sensors as ethanol production is globally viewed as an important industrial activity. Potential industrial applications are highlighted in the context of the emergence of the internet of things (IoT), which is driving widespread utilization of these sensors in the commercially significant industrial and medical sectors. The review concludes with a summary of the current status and future prospects of optical fibre ethanol sensors for industrial use.
\end{abstract}

Keywords: ethanol sensing; optical fibre sensors; absorption-based sensors; interferometric sensors; fibre grating sensors; plasmonic sensors

\section{Introduction}

Ethanol is a colourless organic chemical, which is often referred to as alcohol or ethyl alcohol. Its attractive solvent properties of being easily soluble in water and other organic compounds means that it is one of the key chemicals used in modern industrial processes and consumer products. Its uses throughout society are manifold, including as a preservative, an anti-bacterial agent, an astringent in personal care products, as an antidote, an anti-infective and rubbing alcohol in medicines, as a solvent in paints, lacquers and varnishes, as well as an ingredient in intoxicating alcohol beverages and as an additive for flavouring and preserving food [1]. Since the 1970s, interest in the use of ethanol as a renewable fuel or partial substitute for gasoline has grown significantly. It is considered widely as a renewable alternative for fossil-based chemicals such as bioplastics and an additive for ethanol fuel blends [2,3]. In addition, the traditional drinks industry produces ethanol from yeast fermentation in brewing and wine manufacture and the distillation of spirits leads to a huge range of ethanol fortified alcoholic beverages [4].

The proliferation of ethanol uses as described above also increases the demand for its measurement in other sectors such as environmental health and safety, emission control, 
new biofuel production processes, in pharmaceutical and industrial product development, in breath analysis and in food quality assessment [5]. Analysis of ethanol in many processes is necessarily mandated by the relevant regulating agencies, e.g., the food and drugs administration (FDA) in the USA. A variety of methods can be used to measure the concentration of ethanol in aqueous solution. Commonly used detection methods include enzymatic measurement [6], Raman spectroscopy [7], UV/NIR spectroscopy [8], dichromatic oxidation spectrophotometry [9], refractive index (RI) analysis [8], gas chromatography (GC) [10], high-performance liquid chromatography (HPLC) [11], pycnometry [12], densimetry [12], hydrometry [12], capillary electrophoresis [13] and colorimetric methods [14]. However, the use of these methods has many disadvantages including low reproducibility, potential sample loss, long analysis time, complex offline sample preparation procedures and bulky and expensive instrumentation. Dichromatic oxidation spectrophotometry, pycnometry, hydrometry and densimetry suffer from large sample loss and require a moderate to long time for analysis $[9,12,15,16]$. The accuracy of the measurement is also highly dependent on the operator's knowledge and the sample's temperature [17]. Enzymatic methods are characteristically known for their low accuracy, reproducibility and enzyme stability. Modular Raman spectrometry necessitates precautionary measures for laser use and yield a detection limit of only $1 \%(v / v)$ ethanol $[18,19]$. Complicated calibration procedures are needed for near-infrared spectroscopy and, hence, it can be expensive and time consuming [20]. On the other hand, RI analysis is a relatively simple method, but the accuracy is highly dependent on temperature and can only be used for simple solvents (as opposed to complex mixtures) [21]. When compared to standard chromatography techniques such as GC and HPLC, capillary electrophoresis has lower accuracy. GC is currently considered the most reliable method for ethanol concentration measurement in clinical samples and for alcoholic drinks and is, therefore, the most widely used. Despite the benefits of chromatography techniques, they can be relatively slow (often requiring pre-concentration), complex and costly due to the large quantities of expensive organics needed [22]. Ethanol detection using stimuli-responsive hydrogels and piezoresistive pressure sensors has also been recently reported, where the ethanol concentration of a vodka product ("Wodka Gorbatschow") with a specified value of $37.5 \mathrm{vol} \%$ ethanol was measured [23]. Many industries and research sectors, e.g., alcoholic beverage production and clinical/medical applications, require a simpler, more convenient and higher throughput determination of ethanol concentration [9]. The advantages and disadvantages of the commonly used ethanol detection methods are summarised in Table 1.

Table 1. Summary of commonly used ethanol measurement techniques.

\begin{tabular}{|c|c|c|}
\hline Ethanol Measurement Techniques & Advantages & Disadvantages \\
\hline Enzymatic method & Selectivity and sensitivity [6]. & $\begin{array}{l}\text { Low accuracy, reproducibility and enzyme } \\
\text { stability issues. } \\
\text { Non-specific interference [24]. }\end{array}$ \\
\hline Raman spectroscopy & $\begin{array}{c}\text { Specificity and require small sample } \\
\text { volume [19]. }\end{array}$ & $\begin{array}{l}\text { Precautionary measures required for laser } \\
\text { use and difficulty to measure low } \\
\text { concentrations of ethanol }[18,19]\end{array}$ \\
\hline UV/NIR spectroscopy & $\begin{array}{c}\text { Good sensitivity and less sample } \\
\text { preparation. } \\
\text { Non-destructive method [8]. }\end{array}$ & $\begin{array}{l}\text { Complicated calibration procedures, } \\
\text { expensive and time consuming [20]. }\end{array}$ \\
\hline $\begin{array}{l}\text { Dichromatic oxidation } \\
\text { spectrophotometry }\end{array}$ & $\begin{array}{l}\text { Inexpensive, high accuracy and do not } \\
\text { require skilled analysts [25]. }\end{array}$ & $\begin{array}{l}\text { Sample loss and moderate time for analysis. } \\
\text { Potassium dichromate oxidation: } \\
\text { non-environmentally friendly due to the } \\
\text { carcinogenicity of Chromium (Cr) (VI) [26]. }\end{array}$ \\
\hline
\end{tabular}


Table 1. Cont.

\begin{tabular}{|c|c|c|}
\hline Ethanol Measurement Techniques & Advantages & Disadvantages \\
\hline Refractive index (RI) analysis & Simple and easy method [21]. & $\begin{array}{l}\text { Accuracy highly dependent on } \\
\text { temperature and not suitable for complex } \\
\text { solvent mixtures [21]. }\end{array}$ \\
\hline Gas chromatography (GC) & High accuracy and sensitivity [10]. & $\begin{array}{c}\text { Expensive instrumentation, laborious and } \\
\text { long analysis time [27]. }\end{array}$ \\
\hline $\begin{array}{l}\text { High performance liquid } \\
\text { chromatography (HPLC) }\end{array}$ & $\begin{array}{l}\text { High accuracy and reproducibility. Less } \\
\text { time consuming in comparison to other } \\
\text { chromatographic methods [22]. }\end{array}$ & $\begin{array}{l}\text { Expensive, requiring large quantities of } \\
\text { expensive organics. } \\
\text { Complex to troubleshoot problems [22]. }\end{array}$ \\
\hline Pycnometry & Simple method [12]. & $\begin{array}{l}\text { Long-time analysis, susceptible to error } \\
\text { and requires experienced technicians and, } \\
\text { hence, is expensive [12]. }\end{array}$ \\
\hline Densimetry & Rapid, accurate and simple method [12]. & $\begin{array}{l}\text { Requires large sample volume and } \\
\text { pre-treatment process [20]. }\end{array}$ \\
\hline Hydrometry & Easy to use and inexpensive [12]. & $\begin{array}{l}\text { Requires large amounts of samples and is } \\
\text { susceptible to user error [25]. }\end{array}$ \\
\hline Capillary electrophoresis & Inexpensive and quicker than HPLC [22]. & $\begin{array}{l}\text { Low reproducibility issues [28]. } \\
\text { Lower accuracy than GC and HPLC [22]. }\end{array}$ \\
\hline Colorimetric methods & $\begin{array}{l}\text { Requires small quantity of sample and is } \\
\text { sensitive [29]. }\end{array}$ & $\begin{array}{l}\text { Non-selective and requires pre-distillation } \\
\text { of sample [29]. }\end{array}$ \\
\hline $\begin{array}{l}\text { Hydrogel-based and piezoresistive } \\
\text { pressure sensors }\end{array}$ & $\begin{array}{l}\text { Low cost, small size and inline process } \\
\text { capability [23]. }\end{array}$ & Measurement uncertainty [23]. \\
\hline
\end{tabular}

Recent advances in industrial practice including the emergence of Industry 4.0 for process automation and manufacture has meant that real-time monitoring is a crucial part of those processes. Big data is a major element of the Industrial Internet of Things (IIoT), which results from the generation and collection of massive data sets from sensors used in diagnosis, process monitoring, product manufacturing, health, safety, and quality control. Bulk optical sensing technology has the unique advantage of being immune to external electromagnetic interference and is potentially highly accurate, specifically in resolving very small changes in RI compared to existing commercially available technologies, but typically requires delicate alignment and coupling mechanisms, which increase sensor size, complexity and reduce stability, e.g., through susceptibility to mechanical vibration. On the other hand, optical sensors based on optical fibres are becoming a highly versatile, rugged and potentially cost-effective alternative due to their capability for being miniaturised, readily integrated with electro-optical components or electronic systems, feasible for realtime and remote sensing, and light weight, as well as having a minimised need for precise alignment and coupling [30,31].

Optical fibres have been investigated for their potential use in sensing applications since the early 1980s, and several advances have been made in the fields of optical fibre chemical sensing and biosensing [32]. At that time, researchers also started exploring the concept of optical fibre-based ethanol sensors [33,34]. Wolfbies et al. (1988) used enzymatic oxidation of ethanol to create an optical fibre ethanol biosensor [34]. The sensor layer included an oxygen-sensitive fluorescing indicator that detected a drop in local oxygen partial pressure due to enzymatic oxidation. The sensor detected ethanol concentrations in the range of 50 to $500 \mathrm{mmol} \mathrm{L}^{-1}$, with an accuracy of $\pm 4 \mathrm{mmol} \mathrm{L}^{-1}$ at $100 \mathrm{mmol} \mathrm{L}^{-1}$. Since then, a diverse range of mechanisms have been investigated for measuring ethanol concentration using optical fibre sensors and, in some cases, real applications have been further explored using these sensing schemes. In general, these sensors have delivered encouraging results and demonstrated great potential for ethanol sensing in a wide range of applications. Figure 1 is a graphical summary of a selection of applications for ethanol 
sensing and optical fibre sensing schemes utilised for ethanol sensing extracted from recent literature [35-43] and includes sensor design parameters and typical output responses. Several articles have recently outlined and reflected on the advancement of optical fibre chemical and biosensors from various perspectives [31,32,44-48]. There are abundant possibilities and potential for fabricating highly effective optical fibre ethanol sensors in view of the rapid development of this technology and related functional materials [31]. This article focuses on a review of recent optical fibre sensing developments for ethanol measurement in aqueous solutions, including a perspective on their design and response characteristics. A comparison of their respective performance is provided, which points to their applicability for use in current and future full-scale industrial measurement systems. The continuously developing needs of real time measurement and the emergence of the internet of things (IoT) sets the background to this article, which is intended to inspire and focus further research and wider utilization of these sensors in the commercially significant industrial and medical sectors.

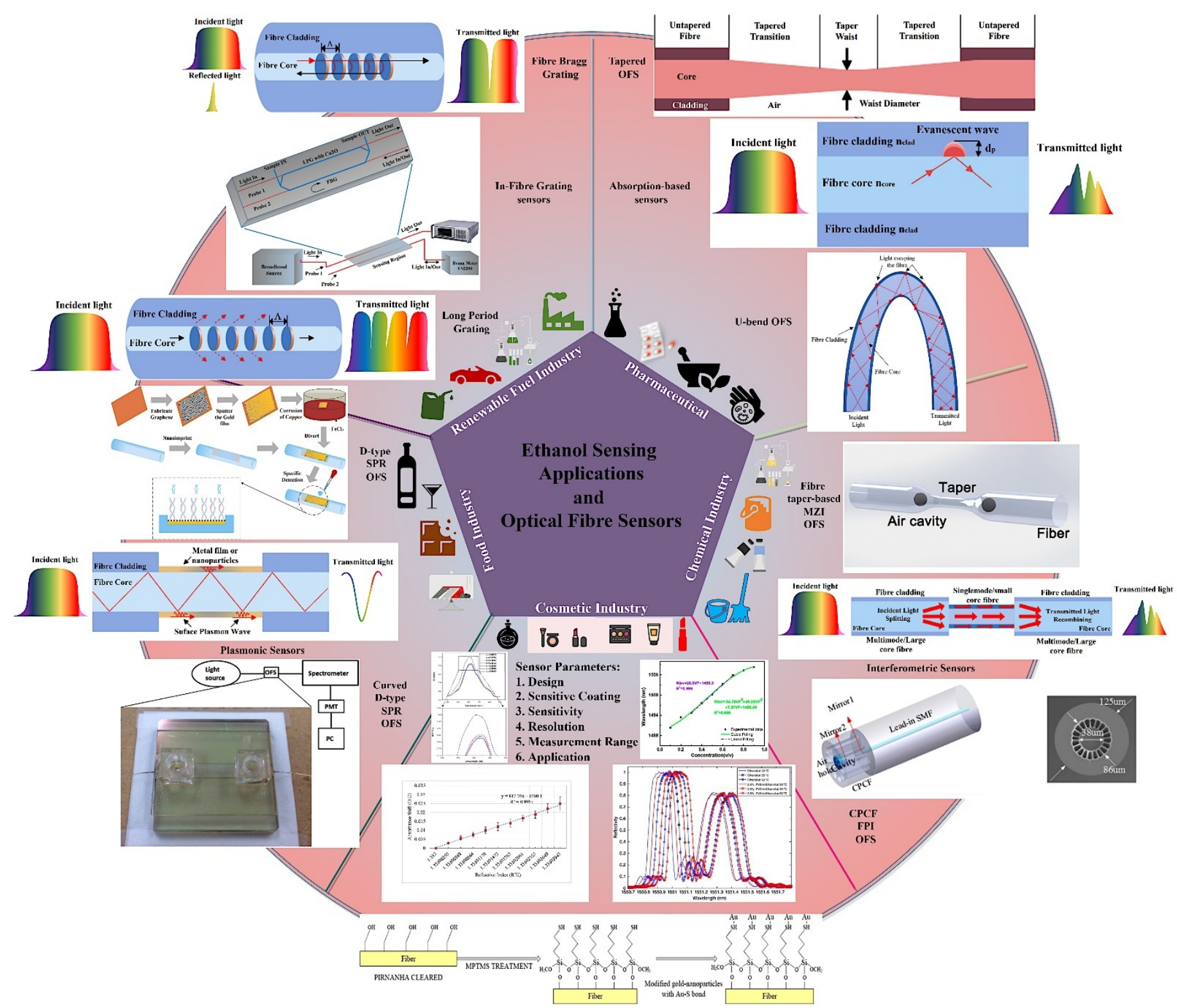

Figure 1. Optical fibre ethanol sensing schemes, applications of ethanol sensing and sensor parameters. Some data extracted from Refs. [35-43]. 


\section{Optical Fibre Sensing Methods}

A basic optical fibre sensor system includes a light source, a sensor element and a detector. An optical fibre sensor interprets a change in the target analyte as a modulation of an optical signal and outputs the modulated optical signal for transmission to humans, computers or other devices in real time, sometimes over long distances [31]. Optical fibre sensors are generally made of glass or plastic optical fibres. A detailed description of the working principles of optical fibre sensors is widely available in the existing literature [49-51] and is beyond the scope of this review.

Conventional optical fibres used in communications and sensing have been historically based on a classical solid core and solid cladding structure. However, there have been some exceptions to these, e.g., UV-transmitting fibres [52]. Microstructure Optical Fibres (MOFs) represent a relatively recent development in optical fibre technology. Microstructured fibres (MSFs) are different from conventional optical fibres in their principle of light propagation. Propagation is supported either by a difference in the effective RI between the solid core and the surrounding honeycomb structure or via the photonic bandgap phenomenon in the case of hollow-core MOFs (where the solid core is replaced by a hollow). There are many variations on this structure, e.g., suspended-core MSFs or hollow-core MSFs, but a detailed description of these is beyond the remit of this review and further details are widely available in the existing literature [53].

There are various techniques available to realise the sensing function of these fibres by enhancing the evanescent field. This includes adopting variations in fibre geometry or shape in the sensing region including bending, polishing, etching, tapering and adding femtosecond laser-inscribed gratings. These techniques have been explored to measure ethanol concentration depending on the sensitivity, selectivity and specific application requirements. They can be categorised as absorption-based sensors, interferometric sensors, fibre grating sensors and plasmonic sensors. The following section includes a review of these sensor categories including tabular-based comparisons of design and response characteristics.

\subsection{Absorption-Based Sensors}

Absorption-based optical fibre ethanol sensors can be described using attenuated total reflection theory. This phenomenon is based on the attenuation of light due to the absorption of the evanescent wave field in the surrounding medium of the fibre or due to light absorption in sensitive material surrounding the fibre. A small amount of light energy is lost from the core during each TIR occurrence. As a result, variations in ethanol concentration modulate the light intensity arriving at a distal detector. An evanescent wave is generated when the energy of the propagating light signal is present in the cladding or other surrounding medium, which creates its own electromagnetic field in that region, as shown in Figure 2.
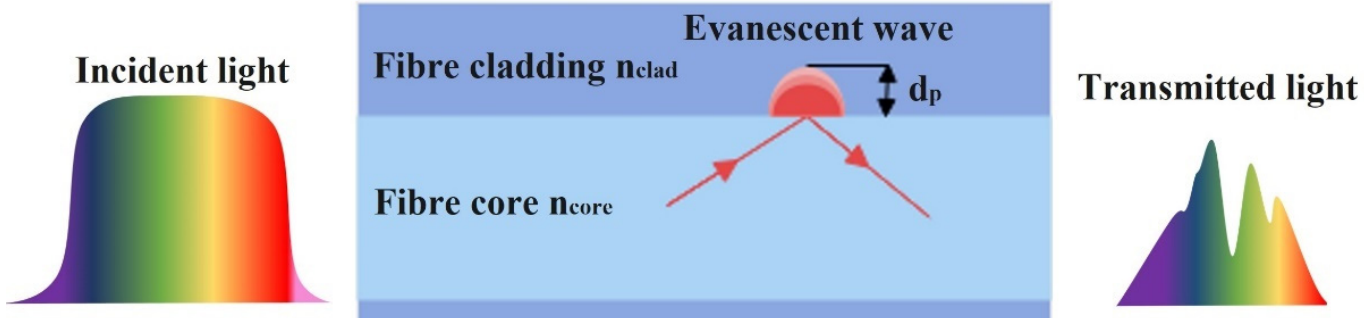

Fibre cladding nclad

Figure 2. Schematic diagram of evanescent wave principle in absorbance-based optical fibre sensors. 
The evanescent field strength of a standard solid core optical fibre, with a core and cladding, decays exponentially as the distance from the core increases and can be expressed as:

$$
I_{x}=I_{0} e^{-x / d_{p}}
$$

where $I_{0}$ is the intensity at the interface, $I_{x}$ is the optical intensity at a perpendicular distance of $x$ from the interface and $d_{p}$ is the penetration depth, which is the distance at which the intensity drops to 1 /e of its initial value at the core and cladding interface. The penetration depth $d_{p}$ can be expressed as:

$$
d_{p}=\frac{\lambda}{2 \pi n_{1} \sqrt{\sin ^{2} \theta-\left(\frac{n_{2}}{n_{1}}\right)^{2}}}
$$

where $\lambda$ is the wavelength of the incident light in vacuum, $\theta$ is the incident angle of the light (in case of MMF), $n_{1}$ and $n_{2}$ are the RI of the fibre core and cladding, respectively. It can be seen from Equation (2) that the penetration depth is dependent on the incident angle of the light at the interface $(\theta)$, and the contrast between the core and cladding RIs. The penetration depth increases with decreasing incident angle and contrast between the core and cladding refractive indices. This can be achieved by modifying the fibre geometry or removing the fibre cladding and coating the core with a higher RI sensitive material. Equations (1) and (2) show that the attenuation of the transmitted light signal is dependent on the surrounding RI of the fibre core. Geometrical modification of the fibre with sensitive coatings such as nanostructures greatly enhances the interaction of the evanescent field with its surroundings and, hence, increases the sensitivity of the ethanol sensor. An absorption-based optical fibre sensor is characterised in terms of the change in intensity (or wavelength distribution of the intensity) at the receiver with the change in ethanol concentration. This change in absorption can manifest as a pure intensity change (no spectral modulation) or as a change in the transmitted light spectrum, e.g., through the appearance of dips or absorption edges in the received spectrum. Many geometrical deformations of optical fibres have been reported in the literature to enhance the sensitivity of absorbance-based ethanol sensors such as U-shaped, coil-shaped, meander-shaped and tapering sensors as well as a combination of bending and tapering sensors [35,41,54-56].

Based on the concepts outlined above, several absorption-based optical fibre ethanol sensors have been proposed. In 2004, MacDonald et al. used tapered chalcogenide glass fibres to record the spectra of water-ethanol mixtures using infrared fibre evanescent wave spectroscopy (FEWS). Te2As3Se5 (TAS) glass rods were drawn into a fibre with a diameter of around 400 micrometres and the fibre was tapered to a diameter of 200 micrometres along its circumference. The agreement between calculated and experimental spectra suggested that the proposed measurement approach was more accurate than other existing techniques investigated [57]. Fabian et al. demonstrated U-bent, coil-shaped and meander-shaped sensors for ethanol and methanol measurement in fuel cell applications using quartz/quartz fibres of $600 \mu \mathrm{m}$ diameter [54,58]. The meander shaped sensor exhibited higher sensitivity in comparison to U- and coil-shaped sensors, owing to a higher concentration of bends in the sensing area. The meander-shaped sensor allowed for the measurement of ethanol concentrations of less than $0.2 \%$ in water at $650 \mathrm{~nm}$ using the visible wavelength region (VIS). Sensors were characterised for ethanol concentrations ranging from 0 to $10 \%$ [54]. Luo et al. used a solid-core photonic crystal fibre (PCF) with large holes to measure ethanol concentration [49] and could detect ethanol solutions of various concentrations, ranging from 0.1 to $1 \%$. It exhibited a sensitivity of $0.461 \mathrm{~dB}$ per $\%$ change in concentration. The optical properties of the PCF were also studied using the finite element method for potential use in future biosensing applications [59].

Girei et al. used a tapered silica multimode optical fibre sensor design (the generic form of which is shown in Figure 3a) to measure ethanol concentration in water. The sensor had a taper length of $20 \mathrm{~mm}$ and a waist diameter of $40 \mu \mathrm{m}$ [35] and responded 
linearly and reversibly towards aqueous ethanol in the range of $5-40 \%$, and the typical response and recovery time were $14 \mathrm{~s}$ and $27 \mathrm{~s}$, respectively. In a follow-on publication, the authors compared the characteristics of graphene and graphene oxide (GO) as the coating materials in the case of multimode tapered optical fibre sensors [60]. The results showed that the GO-coated tapered sensor had higher absorption magnitude changes compared to the graphene-coated tapered sensor, owing to the higher surface area in the GO film, as shown in Figure 3b,c. The GO-coated sensor exhibited higher sensitivity for ethanol concentration in the range of $5 \%$ to $40 \%$ and a faster recovery time with a similar response time as the graphene-coated sensor [60]. Gao et al. fabricated a U-bent plastic clad silica fibre which was coated with GO to enhance the sensitivity [61]. The absorption spectra and the dynamic absorption reaction of the U-bent optical fibre sensor with and without GO film were compared for aqueous ethanol with concentrations ranging from $5 \%$ to $100 \%$. The sensor with the GO film exhibited superior resolution and sensitivity with shorter response and recovery times, which were in the range of 1-2 s. Molybdenum disulfide $\left(\mathrm{MoS}_{2}\right)$ film is considered to be more easily biomodified, chemically stable and requires low synthesis temperature than graphene. Li et al. proposed a U-bent tapered multimode fibre (TU) coated with a molybdenum disulfide $\left(\mathrm{MoS}_{2}\right)$ film $\left(\mathrm{MoS}_{2} @ \mathrm{TU}\right.$ fibre EWA sensor) [55]. A silica glass MMF of $62.5 / 125 \mu \mathrm{m}$ core/cladding diameter was initially tapered over a $3 \mathrm{~mm}$ length with a waste diameter of $50 \mu \mathrm{m}$ and then bent to form a U-bent structure. A comparison between bare U-bent fibre, U-bent fibre with $\mathrm{MoS}_{2}$ film and TU fibre with $\mathrm{MoS}_{2}$ film was made for the measurement of ethanol concentrations in water ranging from 0 to $100 \%$. The $\mathrm{MoS}_{2} @ \mathrm{TU}$ fibre EWA sensor exhibited a higher change in absorption, i.e., $34 \%$ and higher sensitivity, i.e., 0.34 (change in absorption $\Delta \mathrm{A} \% /$ change in concentration $\Delta \mathrm{C} \%$ ) in comparison to the bare and U-bent fibre with a $\mathrm{MoS}_{2}$ film, which was stated as 0.22 . This sensor was also found to be sensitive towards adenosine which the authors' state make them an interesting candidate for bio-sensing applications.

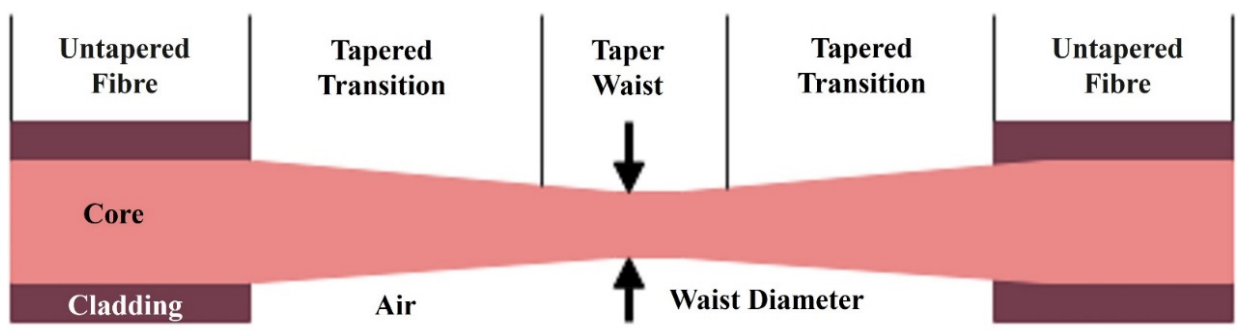

(a)

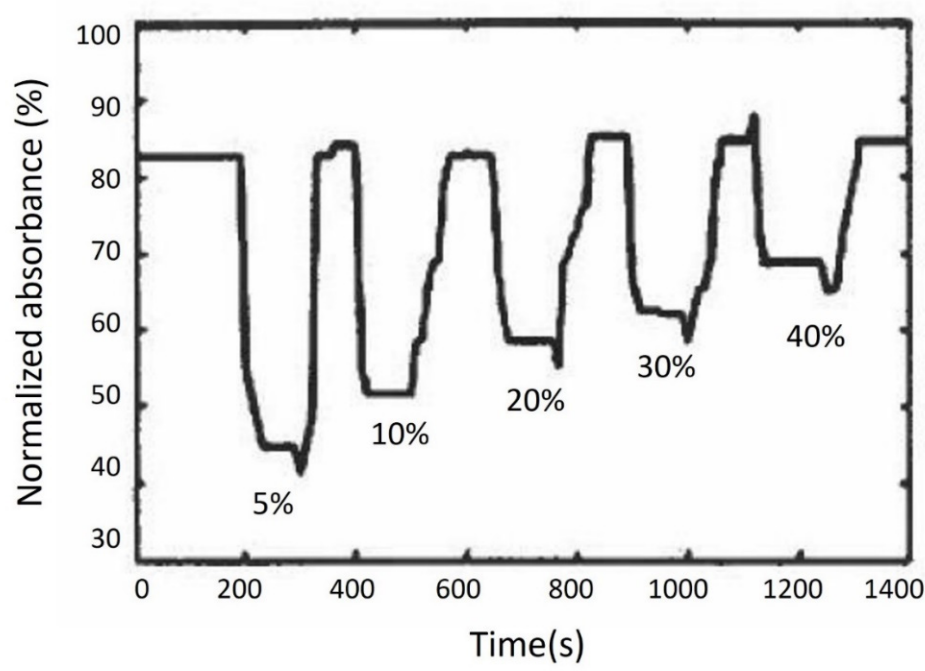

(b)

Figure 3. Cont. 


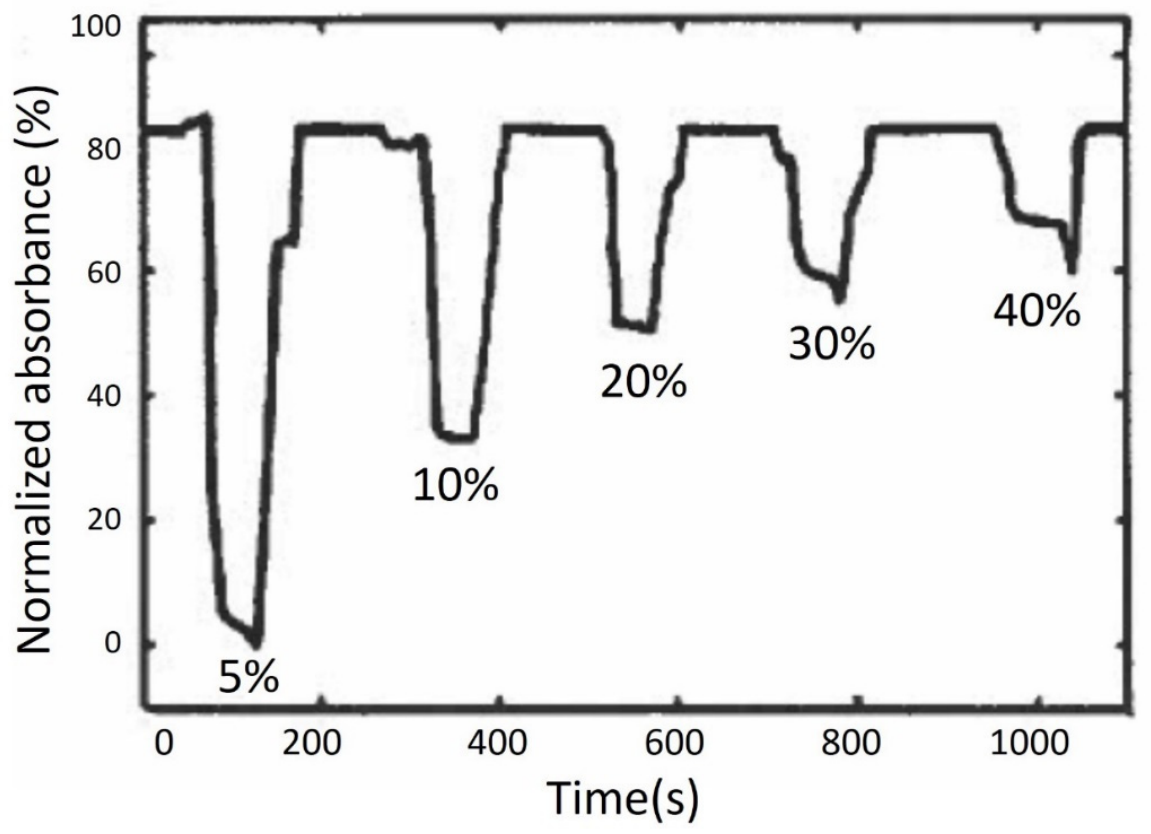

(c)

Figure 3. (a) Schematic diagram of tapered optical fibre ethanol sensor. Dynamic response of (b) graphene- and (c) GO-coated tapered optical fibre sensors for different ethanol concentrations in water. Reprinted, with permission, from Springer Nature: Optical Review Ref. [60]; copyright 2015.

A Plastic Optical Fibre (POF) with $1 \mathrm{~mm}$ overall diameter was investigated for use as an ethanol concentration sensor by Memon et al. [41,62]. A U-bent POF ethanol sensor for real-time sensing in biofuel production applications was designed as shown in Figure 4 a. The sensor was characterised for measurement in the initial stages of bioethanol production, i.e., in the concentration range of $0.005 \%$ to $0.05 \%(w / w)$ in water. In the absence of reported literature on the minute RI changes, they theoretically estimated the RI values for the same range using Lorentz-Lorenz equations and related them to the absorbance response of the sensor. The sensor exhibited a resolution of $10^{-7}$ Refractive Index Unit (RIU) with 99.76\% linearity in the response. The sensitivity and limit of detection (LOD) were found to be 817.76 Optical Density/Refractive Index Unit (O.D./RIU) and $9.2 \times 10^{-7}$ RIU, respectively, as shown in Figure $4 \mathrm{~b}$. Khalaf et al. showed carbon nanotubes (CNT) to be sensitive to aqueous ethanol solutions in the range of $20 \%$ to $100 \%$ when they were coated on an unclad multimode POF (UCPOF) using a drop-casting technique [56]. The GO nanomaterial was also synthesised and used as a sensing layer to obtain a comprehensive view of the CNT-based sensor's performance. Experiments showed that the CNT-based UCPOF sensor exhibited a four-fold higher sensitivity to aqueous ethanol than the GO-coated sensor. The UCPOF sensors based on CNT were also characterised using other Volatile Organic Compounds (VOCs) and they achieved a higher selectivity for ethanol than other analytes tested. The presence of gold nanoparticles (AuNPs) grown in situ on tungsten disulfide $\left(\mathrm{WS}_{2}\right)$ resulted in an enhanced optical coupling between the evanescent wave and the AuNPs, making a U-bent optical fibre EWA sensor significantly more sensitive to environmental changes [63]. Ethanol and $\mathrm{NaCl}$ were used to illustrate the sensing capabilities of the proposed AuNPs on $\mathrm{WS}_{2} @ U$-bent optical fibre EWA sensors. The absorption spectra were captured for the $\mathrm{WS}_{2} @ U$-bent fibre, AuNPs $/ \mathrm{WS}_{2} @ U$-bent fibre for the reaction time of $30 \mathrm{~s}$ and $\mathrm{AuNPs} / \mathrm{WS}_{2} @ \mathrm{U}-$ bent fibre for the reaction time of $60 \mathrm{~s}$ for the ethanol concentration in the range of $10-80 \%$, as shown in Figure 5. The AuNPs $/ W S_{2} @ U-$ bent fibre sensor for the reaction time of 60 showed the highest sensitivity of 0.65 for detecting ethanol solution $(\Delta \mathrm{A} / \Delta \mathrm{C})[63]$. 


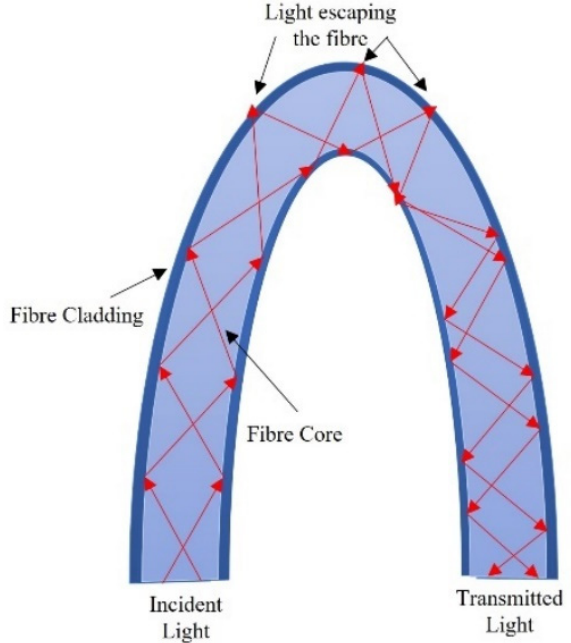

(a)

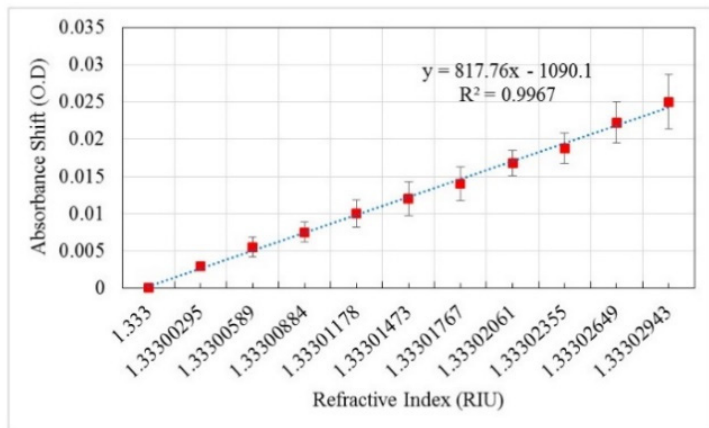

(b)

Figure 4. (a) Schematic of U-bent POF absorbance-based sensor. (b) Absorbance shift response versus change in ethanol concentration. (c) 2018 IEEE. Reprinted, with permission, from Ref. [41].
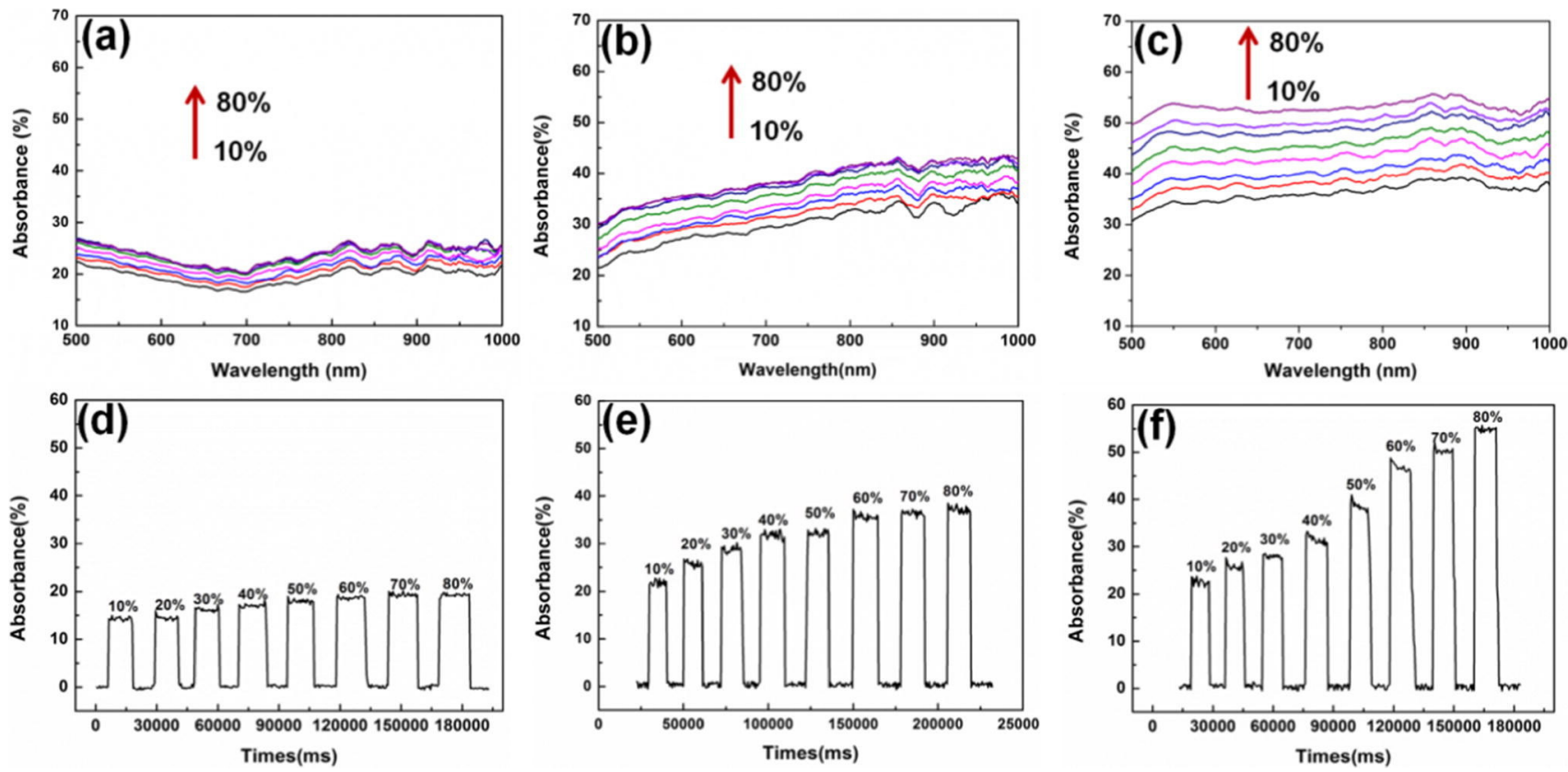

Figure 5. Absorbance spectra for $10 \%$ to $80 \%$ of ethanol concentration using (a) $\mathrm{WS}_{2} @ \mathrm{U}-$ bent fibre for 30 s reaction time, (b) AuNPs $/ \mathrm{WS}_{2} @ U$-bent fibre for the 30 s reaction time and (c) AuNPs/WS $@ @$ Ubent fibre for the $60 \mathrm{~s}$ reaction time. The graphs (d-f) represent temporal responses at $800 \mathrm{~nm}$ wavelength based on the (a), (b) and (c) spectra, respectively. Reprinted from Ref. [63], copyright 2018, with permission from Elsevier.

The examples illustrated above demonstrate the feasibility of optical fibre-based methods based on absorption for aqueous ethanol concentration measurement. These examples are further summarised in Table 2 and classified according to details of structure design, fibre type, sensitive coating, light sources and detectors, sensitivity (S), resolution (R), measurement range and type of application. Table 2 shows that absorption-based optical fibre ethanol sensors are highly versatile in terms of their ease of design and implementation using robust materials. However, deformation of the fibre to improve the 
sensitivity, e.g., through tapering can make the sensor fragile and susceptible to breakage. Low selectivity is also a concern with sensors in the absence of a selective material coating.

Table 2. Summary of absorption-based optical fibre ethanol sensors.

\begin{tabular}{|c|c|c|c|c|c|c|c|c|}
\hline Sensor Design & Fibre Type & $\begin{array}{l}\text { Sensitive } \\
\text { Coating }\end{array}$ & $\begin{array}{l}\text { Light Source and } \\
\text { Detector }\end{array}$ & $S^{*}$ & $\mathbf{R} * *$ & $\begin{array}{l}\text { Measurement } \\
\text { Range }\end{array}$ & Application & Ref. \\
\hline Tapered & $\begin{array}{l}\text { Chalcogenide } \\
\text { glass fibre } \\
(400 \mu \mathrm{m} \text { and } \\
200 \mu \mathrm{m} \text { taper })\end{array}$ & None & $\begin{array}{l}\text { Infrared Light and } \\
\text { Mercury-Cadmium } \\
\text { Telluride Infrared } \\
\text { Detector }\end{array}$ & - & - & $5-50 \%$ & General & [57] \\
\hline $\begin{array}{l}\text { U-, Coil- and } \\
\text { Meander- } \\
\text { Shaped }\end{array}$ & $\begin{array}{l}\text { Quartz/quartz } \\
\text { fibre }(600 \mu \mathrm{m} \\
\text { core })\end{array}$ & None & $\begin{array}{c}\text { Deuterium Halogen } \\
\text { Lamp, } 650 \mathrm{~nm} \text { LED, } \\
\text { SR2000-TR } \\
\text { Spectrometer and UV } \\
\text { enhanced silicon } \\
\text { Photodiode } \\
\text { (UVS-025) }\end{array}$ & - & $10^{-5} \mathrm{RIU}$ & $0-10 \%$ & $\begin{array}{c}\text { Fuel cell } \\
\text { concentration }\end{array}$ & {$[54,58]$} \\
\hline $\begin{array}{l}\text { Straight } \\
\text { Grapefruit } \\
\text { type (PCF) }\end{array}$ & $\begin{array}{c}\text { PCF } \\
(10 \mu \mathrm{m} \text { core } \\
\text { and } 121 \mu \mathrm{m} \\
\text { cladding })\end{array}$ & None & $\begin{array}{l}\text { Light Source of } \\
632.8 \mathrm{~nm}\end{array}$ & $0.461 \mathrm{~dB} / \mathrm{vol} \%$ & - & $0.1-1 \%$ & Biosensing & [59] \\
\hline Tapered & $\begin{array}{l}\text { Multimode } \\
\text { (MM) Silica } \\
\text { fibre } \\
(62.5 \mu \mathrm{m} \text { core } \\
\text { and } 125 \mu \mathrm{m} \\
\text { cladding) }\end{array}$ & $\begin{array}{c}\text { None, } \\
\text { Graphene and } \\
\text { GO }\end{array}$ & $\begin{array}{l}\text { Tungsten Halogen } \\
\text { Lamp and Ocean } \\
\text { Optics USB4000 } \\
\text { Spectrometer }\end{array}$ & $\begin{array}{l}0.829 / \mathrm{vol} \% \text { for } \\
\text { graphene- } \\
\text { coated sensor } \\
\text { and } 1.330 / \text { vol } \\
\% \text { for } \\
\text { GO-coated } \\
\text { sensor }\end{array}$ & - & $5-40 \%$ & General & {$[35,60]$} \\
\hline U-bend & $\begin{array}{l}\text { MM PCS Fibre } \\
(62.5 \mu \mathrm{m} \text { core } \\
\text { and } 125 \mu \mathrm{m} \\
\text { cladding })\end{array}$ & GO & $\begin{array}{l}\text { White LED and } \\
\text { PG2000 Spectrometer }\end{array}$ & - & - & $10-100 \%$ & General & [61] \\
\hline $\begin{array}{l}\text { Tapered } \\
\text { U-bent }\end{array}$ & $\begin{array}{l}\text { MM Silica } \\
\text { fibre } \\
(62.5 \mu \mathrm{m} \text { core } \\
\text { and } 125 \mu \mathrm{m} \\
\text { cladding })\end{array}$ & MoS2 & $\begin{array}{l}\text { Broadband Light } \\
\text { Source }(450 \text { to } \\
1000 \mathrm{~nm}) \\
\text { Ideaoptics } \\
\text { Instruments PG2000 } \\
\text { Spectrometer }\end{array}$ & $\begin{array}{c}0.34 \\
(\Delta \mathrm{A} \% / \Delta \mathrm{C} \%)\end{array}$ & - & $0-100 \%$ & Biosensing & [55] \\
\hline U-bend & $\begin{array}{l}\text { MM POF } \\
\text { (980 } \mu \mathrm{m} \text { core } \\
\text { and } 1000 \mathrm{um} \\
\text { cladding) }\end{array}$ & None & $\begin{array}{l}\text { Tungsten Halogen } \\
\text { Lamp, } 659 \mathrm{~nm} \\
\text { Photodiode and } \\
\text { Ocean Optics } \\
\text { QE65000 } \\
\text { Spectrometer }\end{array}$ & $\begin{array}{l}817.760 \\
\text { O.D/RIU }\end{array}$ & $10^{-7} \mathrm{RIU}$ & $\begin{array}{c}0.005-0.05 \% \\
(w / w) \\
\text { LOD: } 9.2 \times \\
10^{-7} \text { RIU }\end{array}$ & $\begin{array}{l}\text { Bioethanol } \\
\text { production }\end{array}$ & {$[41,62]$} \\
\hline $\begin{array}{l}\text { Unclad } \\
\text { Straight }\end{array}$ & $\begin{array}{l}\text { MM POF } \\
\text { (980 um core } \\
\text { and } 1000 \text { um } \\
\text { cladding) }\end{array}$ & $\begin{array}{l}\text { Carbon } \\
\text { Nanotubes } \\
(\mathrm{CNT})\end{array}$ & $\begin{array}{l}\text { Tungsten Halogen } \\
\text { Lamp and Ocean } \\
\text { Optics USB4000 } \\
\text { Spectrophotometer }\end{array}$ & $0.678 / \mathrm{vol}^{\%} / 0.2 \%$ & - & $20-100 \%$ & General & [56] \\
\hline U-bent & $\begin{array}{l}\text { MM PCS Fibre } \\
\text { (62.5 um core } \\
\text { and } 125 \mathrm{um} \\
\text { cladding) }\end{array}$ & $\begin{array}{c}\text { Gold } \\
\text { nanoparticles } \\
\text { on Tungsten } \\
\text { disulphide } \\
\text { (AuNPs on } \\
\text { WS2) }\end{array}$ & $\begin{array}{l}\text { HL200 Light source } \\
(360 \text { to } 2500 \mathrm{~nm}) \text { and } \\
\text { Ideaoptics } \\
\text { Instruments PG2000 } \\
\text { Spectrometer }\end{array}$ & $0.65(\Delta \mathrm{A} / \Delta \mathrm{C})$ & - & $10-80 \%$ & General & [63] \\
\hline
\end{tabular}

\subsection{Externally Modified Interferometric Sensors}

Optical interferometry is an established method that has achieved high-accuracy measurements in a variety of applications such as temperature and pressure measurement, refractive index measurement, growth rate in crystallization and surface metrology $[64,65]$. Two-beam amplitude-division interferometry is commonly used for sensing applications and can be described as an interference pattern produced by the recombination of two light beams of the same frequency, constant phase difference and identical direction [66]. The resulting intensity can be expressed as follows:

$$
I=I_{1}+I_{2}+2 \sqrt{I_{1} I_{2}} \cos \varnothing
$$


where $I_{1}$ and $I_{2}$ are the intensities of two light beams and $\varnothing$ is the phase difference between $I_{1}$ and $I_{2}$. The phase difference $\varnothing$ is given by:

$$
\varnothing=\frac{N \pi n L}{\lambda}
$$

where $N$ is an integer and its value is dependent on the type of interferometry, $n$ is the RI of the transmitting medium and $L$ is the optical path length over which the phase change occurs. The main interferometric techniques used for optical fibre ethanol concentration measurement include Fabry-Perot, Mach-Zehnder and Michelson. Generally, changes in a sensing layer or film coated on the outside of the fibre in one of the interferometer's arms are monitored with the change in ethanol concentration. A number of different sensing film materials have been investigated for this purpose. Due to the physical absorption/adsorption of ethanol molecules, the sensing layer generally changes one or more of its physical properties (e.g., thickness or volume) or optical properties (e.g., RI) causing a change in optical path length experienced by different wavelengths and, hence, a phase shift in the output spectrum. However, interferometric techniques have also been explored without any sensing film with promising outcomes [36,67-69]. A schematic diagram of a multimode-singlemode-multimode (MSM) sensor is shown in Figure 6.
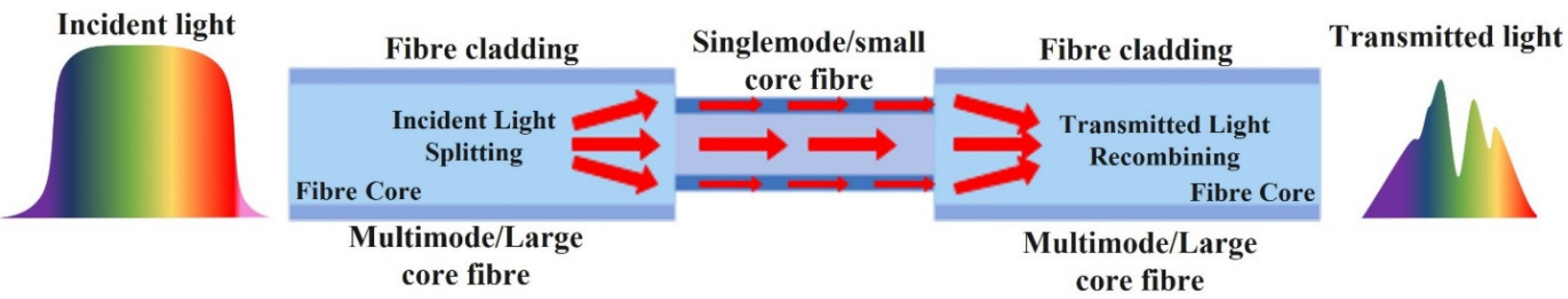

Figure 6. Schematic diagram of a multimode-singlemode-multimode optical fibre sensor [70].

Mudhana et al. proposed a single-arm common-path interferometer optical fibre structure with a cavity (singlemode fibre) length of $1 \mathrm{~mm}$ [67]. A unique large radius bifunctional PCF lens eliminated the requirement for two arms as is the case in a traditional interferometer. This specifically developed PCF lens served as both the reference arm's reflector and the sample arm's collimator. The bifunctional lens tip and a micro-mirror were encased in a glass tube to create the sensor element for detecting the RI of liquids. A hole was drilled in the glass tube to allow the liquid sample to freely flow in and out of the cavity. The RIs of acetone, ethanol and distilled water were measured using the probe and an analytical resolution of $2.6 \times 10^{-5}$ RIU was achieved. The authors further suggested replacing the sensor element with a reflection-coated fibre to reduce the sensor's size. Yuan et al. developed an inline optical fibre Michelson Interferometer (MI) by creating, on a sample-by-sample basis, a step structure at the tip of a standard singlemode optical fibre (Corning SMF-28) with a core/cladding diameter of 8.2/125 $\mu \mathrm{m}$ [71]. A femtosecond laser was used to micromachine a step structure which split the reflected light path into two paths. Both temperature and RI sensing were successfully demonstrated, and ethanol was specifically used for the measurements in the range of $0-50 \%$ in liquid solutions. A nonlinear relationship between wavelength shift and concentration was observed and it was qualitatively related to the Langmuir adsorption model. This design showed a limitation of low sensitivity for RI measurements. The measurements were also recorded rather than monitoring a continuous change in solution concentration.

$\mathrm{Wu}$ et al. proposed an alternative fibre inline interferometer based on an open-cavity Fabry-Perot Interferometry technique [68]. The sensor involved fusion splicing a C-shaped thin fibre between two standard singlemode fibres. In this case, the C-shaped fibre served as an open cavity, which allowed the gap between the two single-mode fibres to be filled by water-ethanol solutions in the RI range of 1.33 to 1.36 . The performance of the sensor 
was also tested by changing the cavity length where a shorter cavity length was observed to increase the measurement range and detection limit. This sensor design demonstrated a maximum sensitivity of $1368 \mathrm{~nm} / \mathrm{RIU}$ at $1600 \mathrm{~nm}$ wavelength with a linear response of $\mathrm{R}^{2}=0.996$ and very low temperature cross-sensitivity of $3.04 \times 10^{-7} \mathrm{RIU} /{ }^{\circ} \mathrm{C}$. The main limitation of this sensor design was that the C-shaped fibre is not a commercial product, and its production is complicated and expensive. Photonic crystal fibres have also been explored for open-cavity FPIs. Tian et al. explored the use of a concave-core photonic crystal fibre (CPCF) as an open-cavity FPI microfluidic RI sensor with a fast reaction time [36]. A small section of multimode PCF was cleaved with an axial tension to create the CPCF and the shallow concave core formed a Fabry-Perot cavity of very short length which broadened the measurement range. The multiple air holes in the CPCF acted as microfluidic channels, allowing liquid samples to be effectively delivered into and out of the sensor. Figure 7 shows the schematic of the CPCF FPI sensor structure and cross-sectional view of the CPCF. This sensor design was characterised using 0 to $19.11 \%$ ethanol in distilled (DI) water and exhibited a sensitivity of $1635.62 \mathrm{~nm} /$ RIU at $1500 \mathrm{~nm}$ wavelength as shown in Figure 8 . The measurement response times for this sensor design were less than $23 \mathrm{~ms}$ and $359 \mathrm{~ms}$ for pure ethanol and distilled water, respectively.

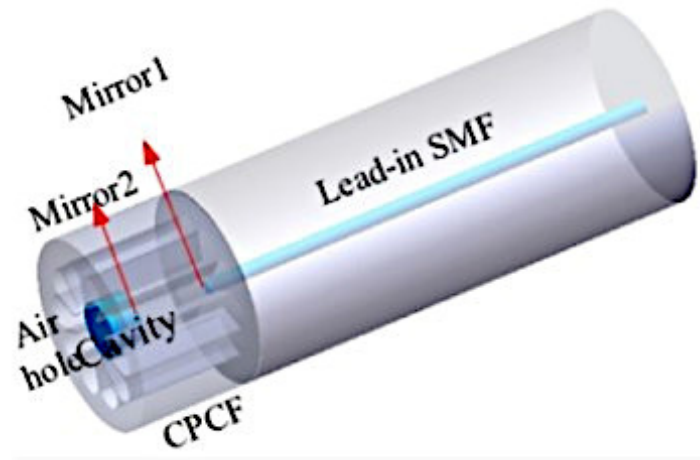

(a)

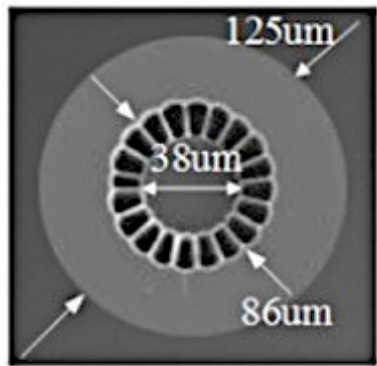

(b)

Figure 7. (a) Schematic structure of the concave-core PCF FPI Sensor. (b) Microscopic cross-sectional view of the CPCF. Reprinted/adapted with permission from [36]; @ The Optical Society.

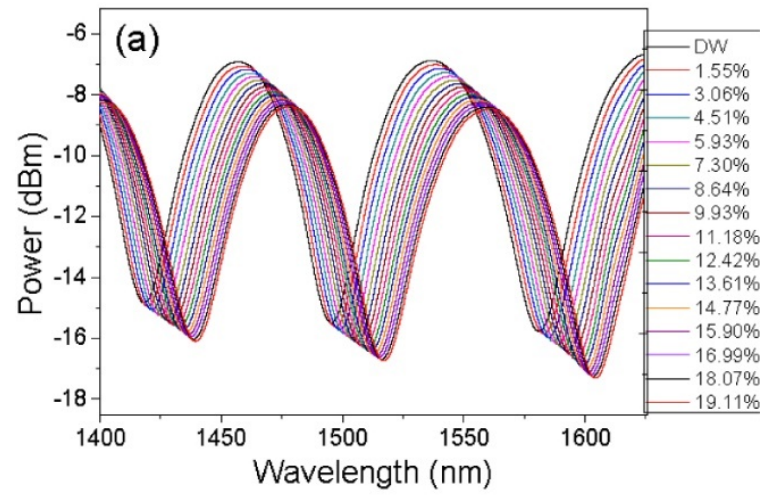

(a)

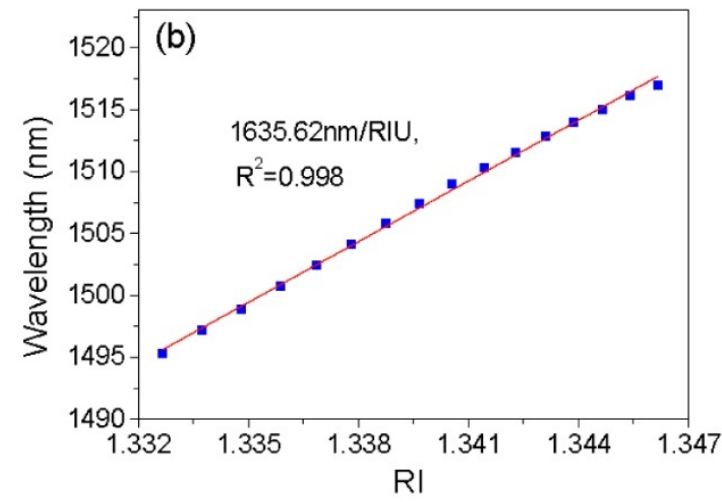

(b)

Figure 8. (a) Reflection spectra of CPCF PFI sensor when exposed to ethanol-water concentrations from 0 to $19.11 \%$. (b) Relationship between the dip wavelength centred around $1500 \mathrm{~nm}$ versus ethanol-water solutions' RI changes. Reprinted with permission from [36]; (c) The Optical Society.

Muri et al. used a hydrogel half-sphere on the fibre end face to form a low-finesse Fabry-Perot cavity [72]. They demonstrated the quality of interferometric and Localised Surface Plasmon Resonance (LSPR) characteristics of gold nanoparticles (GNP) fixed in an 
acrylamide hydrogel of the fibre end-face as a first step for a combined interferometric and LSPR-based optical fibre sensor. The free spectral range (FSR) and LSPR were monitored as a function of hydrogel swelling degree with increasing ethanol concentration from $30 \%$ to $50 \%$. A similar sensor also demonstrated promising results for medical applications in terms of label-free and selective sensing of biomolecules [72].

Multimode interference (MMI) devices have also attracted significant attention due to their ease of fabrication. Rodriguez-Rodriguez et al. proposed such an MMI produced by splicing a short length of MMF between two standard singlemode fibres for monitoring the quality of gasoline/ethanol blends for flexible-fuel vehicles (FFV) [73]. A coreless MMF of $125 \mu \mathrm{m}$ diameter was used as the MMF part of the sensor. The MMI sensor was used for making RI measurements using various chemical solutions and exhibited a sensitivity of $133.65 \mathrm{~nm} / \mathrm{RIU}$ for a 1.318 to $1.373 \mathrm{RI}$ range, and a sensitivity of $390.88 \mathrm{~nm} / \mathrm{RIU}$ for a 1.373 to 1.420 RI range. Solutions ranging from E50 ethanol-gasoline blend to pure G87 gasoline were used for characterization. Reducing the amount of ethanol produced a red shift in the observed spectrum due to the higher RI of pure G87 Gasoline. Marfu'Ah et al. proposed an alternative configuration of MMI based on splicing a short length of singlemode fibre between two multimode fibres as a multimode-singlemode-multimode (MSM) structure where part of the energy of the core mode is transferred to cladding modes [74]. Experiments were performed using the MSM sensor with and without a novolac resin coating. The sensor with the novolac coating indicated higher sensitivity in comparison to the sensor with no novolac resin coating in alcohol-water and alcohol-sugar solutions in the range of 0 to $10 \%$. The sensitivity of the MSM sensor with the novolac resin coating was measured to be $0.028972 \mathrm{dBm}$ per $\% v / v$ and $0.005005 \mathrm{dBm}$ per $\% v / v$ for alcohol-water solutions and alcohol-sugar solutions, respectively.

Liao al. investigated the use of an optical fibre taper-based Mach-Zehnder interferometer (MZI) configuration for ethanol concentration measurement [43]. The MZI was based on a taper and two inner air bubbles created using femtosecond laser processing as well as a combined splicing-tapering technique as shown in Figure 9a. Figure 9b is a microscope image of the structure. A non-linear relationship between the ethanol concentration and dip wavelength was observed when aqueous ethanol solutions of concentrations ranging from $10 \%$ to $90 \%$ were tested. A linear response was observed in the $30 \%$ to $70 \%$ ethanol-water concentration range, as shown in Figure 9c, with a sensitivity of $28 \mathrm{~nm} / \mathrm{vol}$ or $592.8 \mathrm{~nm} /$ RIU. Recently, Zhou et al. proposed a Michelson Interferometer optical fibre probe for RI measurement, where the main highlight was the capability of temperature compensation of liquids during the RI measurement [69]. Zhou et al. developed a cavity using femtosecond laser machining located very close to the end of a cleaved fibre tip. The fibre tip was cleaved at a $45^{\circ}$ angle with respect to the fibre axis. When this sensor was exposed to air it created a Fabry-Perot cavity and behaved as a Michelson interferometer when exposed to liquid. This sensor was not directly interrogated for ethanol as the liquid of interest. However, it was characterised in terms of the RI range for which experimental data matches with typical ethanol RI values. The temperature dependence for ethanol, methanol and water were measured at an interrogating wavelength of $1550 \mathrm{~nm}$, where the measured results agreed well with experimental data from other researchers. However, there was a considerable change in the thermo-optic coefficient of methanol with a theoretical estimate. This sensor exhibited a sensitivity varying from 885.437 to $1067.525 \mathrm{~nm} / \mathrm{RIU}$ when the RI varied from 1.3166 to 1.4346 . 


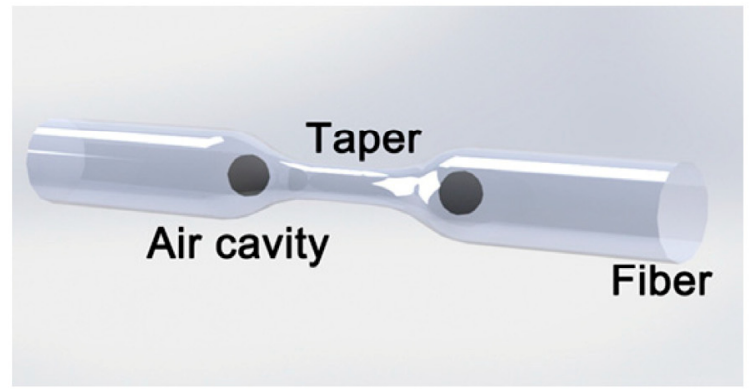

(a)

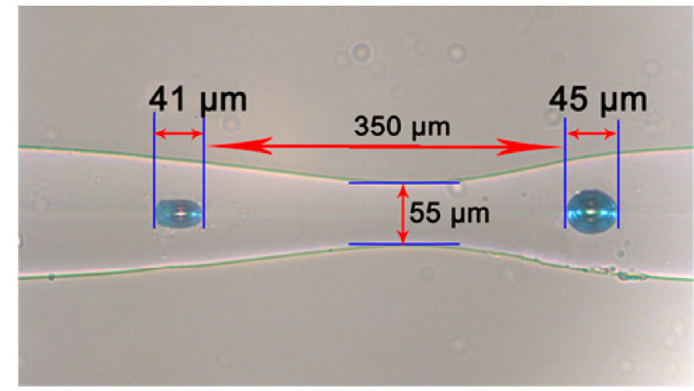

(b)

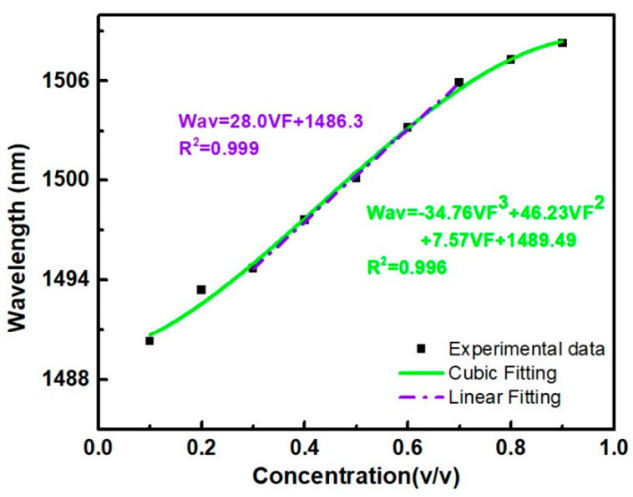

(c)

Figure 9. Fibre taper-based MZI: (a) schematic diagram, (b) microscopic image and (c) shift in the wavelength of the dip near $1485 \mathrm{~nm}$ versus volume fraction of the aqueous ethanol solution. Reproduced from Ref. [43].

The performance of the Interferometric Optical Fibre Ethanol sensors referenced above is further summarised in Table 3 in terms of sensor design, fibre type, sensitive coating, light sources and detectors, sensitivity (S), resolution (R), measurement range and type of application. From the above examples, it must be emphasised that some interferometric techniques require costly, precise and sometimes delicate fabrication process steps such as femtosecond laser machining. On the other hand, multimode interferometers are relatively easy to implement and have simple structures that include flexible design, with a tradeoff of difficult prediction of the output due to the non-periodicity of the spectrum, which can give rise to a highly complex signal.

Table 3. Summary of interferometric optical fibre ethanol sensors.

\begin{tabular}{|c|c|c|c|c|c|c|c|c|}
\hline Sensor Design & Fibre Type & $\begin{array}{l}\text { Sensitive } \\
\text { Coating }\end{array}$ & $\begin{array}{c}\text { Light Source and } \\
\text { Detector }\end{array}$ & $S^{*}$ & $\mathbf{R} * *$ & $\begin{array}{c}\text { Measurement } \\
\text { Range }\end{array}$ & Application & Ref. \\
\hline $\begin{array}{l}\text { Single-arm } \\
\text { common-path } \\
\text { interferometer }\end{array}$ & PCF (LMA-10) & None & Power Meter & - & $2.6 \times 10^{-5} \mathrm{RIU}$ & - & General & [67] \\
\hline $\begin{array}{l}\text { Step structure } \\
\text { fibre inline MI }\end{array}$ & $\begin{array}{c}\text { SMF-28 } \\
\text { (core/cladding } \\
\text { diameter of } \\
8.2 / 125 \mu \mathrm{m} \text { ) }\end{array}$ & None & $\begin{array}{c}\text { Broadband Light Source } \\
\text { and Spectrum Analyser } \\
\text { (OSA, AQ6319) }\end{array}$ & - & - & $0-50 \%$ & General & [71] \\
\hline $\begin{array}{c}\text { Inline } \\
\text { C-shaped } \\
\text { open-cavity } \\
\text { FPI }\end{array}$ & $\begin{array}{l}\text { Fused Silica } \\
\text { tube for } \\
\text { C-shaped cav- } \\
\text { ity and SMF-28 } \\
\text { (core/cladding } \\
\text { diameter of } \\
8.2 / 125 \mu \mathrm{m} \text { ) }\end{array}$ & None & $\begin{array}{c}\text { Broadband } \\
\text { Super-Luminescent } \\
\text { Diode SLD (1420 nm to } \\
1620 \mathrm{~nm}) \text { and Spectrum } \\
\text { Analyser (OSA, } \\
\text { AQ6370) }\end{array}$ & $1368 \mathrm{~nm} / \mathrm{RIU}$ & - & $1.333-1.365 \mathrm{RI}$ & General & [68] \\
\hline
\end{tabular}


Table 3. Cont.

\begin{tabular}{|c|c|c|c|c|c|c|c|c|}
\hline Sensor Design & Fibre Type & $\begin{array}{l}\text { Sensitive } \\
\text { Coating }\end{array}$ & $\begin{array}{l}\text { Light Source and } \\
\text { Detector }\end{array}$ & $S^{*}$ & $\mathbf{R}^{* *}$ & $\begin{array}{c}\text { Measurement } \\
\text { Range }\end{array}$ & Application & Ref. \\
\hline $\begin{array}{l}\text { Concave-core } \\
\text { open-cavity } \\
\text { FPI }\end{array}$ & $\begin{array}{l}\text { PCF }(38 \mu \mathrm{m} \\
\text { solid core } \\
\text { surrounded by } \\
20 \text { petals } \\
\text { shaped } \\
\text { airholes }\end{array}$ & None & $\begin{array}{l}\text { Broadband Light Source } \\
\text { (FiberLake-BBS) and } \\
\text { Spectrum Analyser } \\
\text { (OSA, AQ6370C) }\end{array}$ & $1635.62 \mathrm{~nm} / \mathrm{RIU}$ & - & $0-19.11 \%$ & General & [36] \\
\hline $\begin{array}{l}\text { LSPR-based } \\
\text { FPI }\end{array}$ & $\begin{array}{c}\text { Double- } \\
\text { Cladded } \\
\text { Optical Fibre } \\
\text { (DCOF) } \\
\text { (DCF13, } \\
\text { Thorlabs) }\end{array}$ & $\begin{array}{c}\text { Gold } \\
\text { Nanoparticles } \\
\text { (GNP) }\end{array}$ & $\begin{array}{c}\text { Light Sources (MBB1F1, } \\
470-850 \mathrm{~nm} \text { and } \\
\text { S5FC1005S, } 1550 \mathrm{~nm} \\
\text { Thorlabs) and } \\
\text { Spectrometers } \\
\text { (QE65Pro and } \\
\text { NIRQuest-512-1.7 } \\
\text { Ocean Optics) }\end{array}$ & - & - & $30-50 \%$ & General & [72] \\
\hline $\begin{array}{l}\text { Singlemode- } \\
\text { multimode- } \\
\text { singlemode } \\
\text { (SMS) MMI }\end{array}$ & $\begin{array}{l}\text { SMF-28 and } \\
\text { No-Core MMF } \\
\text { (125 um } \\
\text { diameter) }\end{array}$ & None & $\begin{array}{c}\text { SLD (1465 to } 1650 \mathrm{~nm}) \\
\text { and Optical Spectrum } \\
\text { Analyser (OSA Anritsu } \\
\text { MS9740A) }\end{array}$ & $\begin{array}{c}133.65 \mathrm{~nm} / \mathrm{RIU} \\
\text { for } 1.318 \text { to } \\
1.373 \mathrm{RI} \text { range } \\
\text { and } \\
390.88 \mathrm{~nm} / \mathrm{RIU} \\
\text { for } 1.373 \text { to } \\
1.420 \mathrm{RI} \text { range }\end{array}$ & - & $\begin{array}{l}1.318 \text { to } 1.373 \\
\text { RI, } 1.373 \text { to } \\
1.420 \text { RI and } \\
\text { E50 to pure } \\
\text { G87 }\end{array}$ & $\begin{array}{l}\text { Monitoring of } \\
\text { gaso- } \\
\text { line/ethanol } \\
\text { blends }\end{array}$ & [73] \\
\hline $\begin{array}{l}\text { Multimode- } \\
\text { singlemode- } \\
\text { multimode } \\
\text { MI }\end{array}$ & $\begin{array}{l}\text { SMF and } \\
\text { MMF }\end{array}$ & Novolac Resin & $\begin{array}{l}1310 \text { nm Light Source } \\
\text { and Optical Power } \\
\text { Meter }\end{array}$ & $\begin{array}{c}0.028972 \mathrm{dBm} \\
\text { per } \% v / v\end{array}$ & - & $0-10 \%$ & $\begin{array}{l}\text { Liquid phase } \\
\text { alcohol } \\
\text { detection }\end{array}$ & [74] \\
\hline $\begin{array}{c}\text { Taper-based } \\
\text { MZI }\end{array}$ & SMF & None & - & $\begin{array}{c}28 \mathrm{~nm} / \mathrm{vol} \text { or } \\
592.8 \mathrm{~nm} / \mathrm{RIU}\end{array}$ & - & $30-70 \%$ & General & {$[43]$} \\
\hline $\begin{array}{l}\text { Michelson } \\
\text { Interferometer } \\
\text { (MI) }\end{array}$ & SMF & None & $\begin{array}{l}\text { Broadband Light Source } \\
\text { and Interrogator } \\
(1510-1590 \mathrm{~nm})\end{array}$ & $\begin{array}{c}885.437 \text { to } \\
1067.525 \mathrm{~nm} / \mathrm{RIU}\end{array}$ & - & $\begin{array}{c}1.3166-1.4346 \\
\text { RI }\end{array}$ & General & [69] \\
\hline
\end{tabular}

* Sensitivity, ${ }^{* *}$ resolution.

\subsection{In-Fibre Grating Sensors}

A grating in an optical fibre is formed as a periodic variation in the core RI. Fibre gratings are generated as spatial phase gratings in the core and are formed using the photosensitivity of the fibre materials. General fibre gratings can be classified into two types based on their physical structure (or grating period): Fibre Bragg gratings (FBG) with grating periods in the order of $1.5 \mu \mathrm{m}$ and Long Period gratings (LPG) with grating periods in the order of $100 \mu \mathrm{m}$. Light at a certain wavelength can couple to a backward propagating fundamental mode or a forward propagating cladding mode depending on the grating type. As shown in Figure 10a in the case of an FBG, there is coupling between a forward and backward propagating mode over a narrow band of selected wavelengths only, which creates a peak in the reflection spectrum, giving rise to a specific Bragg-reflective wavelength $\lambda_{B}$, given as [75]:

$$
\lambda_{B}=2 n_{e f f} \Lambda
$$

where $\Lambda$ is the grating period and $n_{\text {eff }}$ is the effective RI. Normal FBGs formed in standard SMFs are inherently insensitive to the RI of the surrounding environment. FBG-based optical fibre ethanol sensors are either developed by reducing the cladding diameter by etching to enhance interaction of the core modes with the surrounding refractive index (SRI) or by coating a sensitive material on the cladding or both. As FBGs are inherently sensitive to strain within the fibre, many FBG sensors are fabricated to respond to a change in volume of the coating material when exposed to the measurand, e.g., ethanol solution, which in turn causes a shift in the reflected spectrum due to a change in the grating period [76].

In the case of LPGs, optical coupling is established between the forward propagating core mode to the cladding modes, which takes place at certain wavelengths only. The pattern of the coupling variation with wavelength is repetitive over the spectral transmission range of the fibre which gives rise to a classical photonic bandgap behaviour of these devices, as shown in Figure 10b. The grating period is defined as distance between the 
points where the core and cladding modes are in phase. The phase-matching condition determines the resonances of the long-period grating, as given below [75]:

$$
\lambda=\Lambda\left(n_{e f f}^{c o}-n_{e f f}^{c l}\right)
$$

where $\Lambda$ is the grating period and $n_{e f f}^{c o}$ and $n_{e f f}^{c l}$ are the effective refractive indices in the core and cladding, respectively. The interaction between the core and cladding modes in the case of an LPG is much stronger than in the case of an FBG and, therefore, LPG-based optical fibre sensors exist with and without coatings.
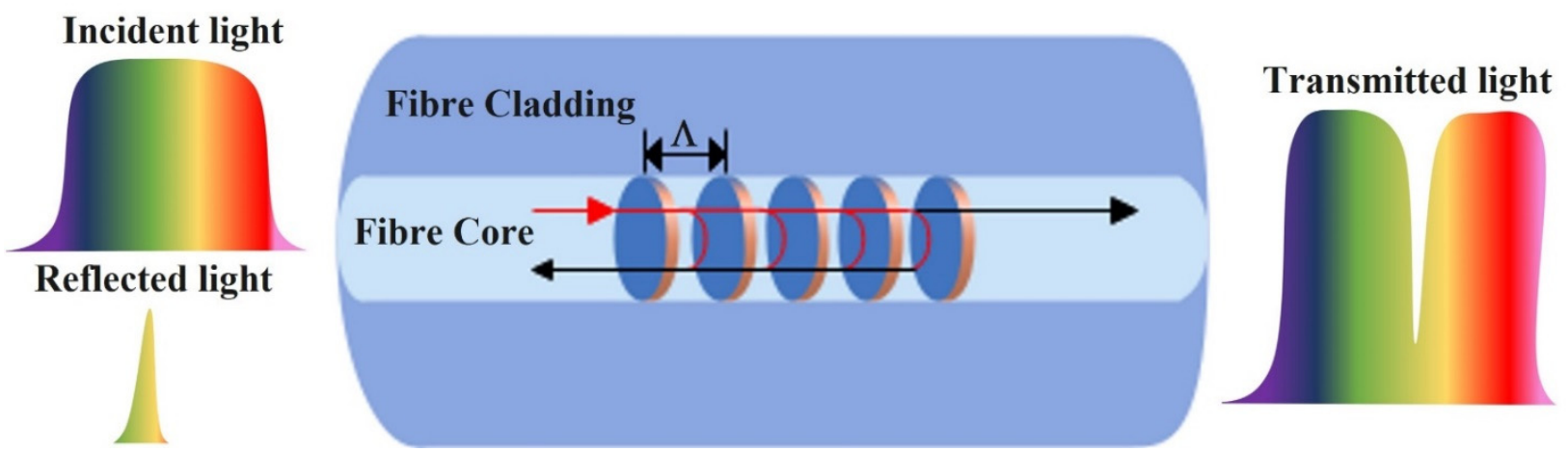

(a)
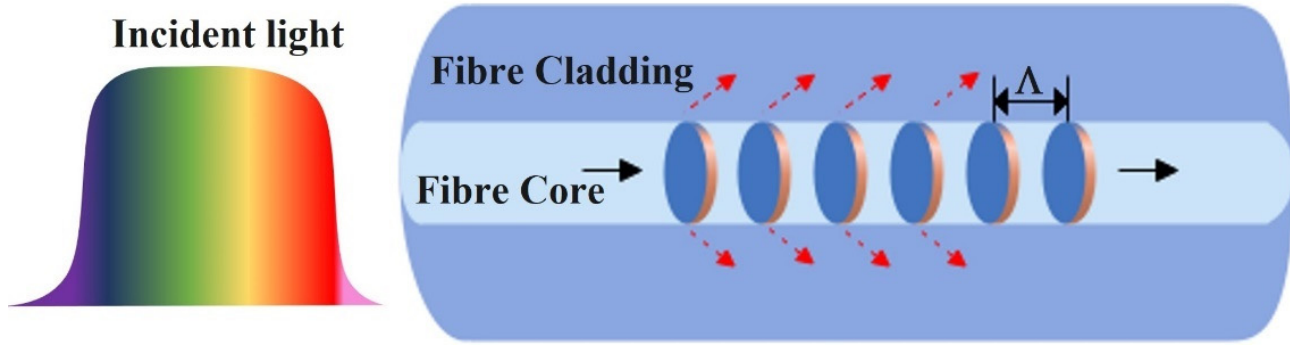

Transmitted light

(b)

Figure 10. Schematic diagrams of (a) FBG sensor and (b) LPG sensor.

In 2003, Keith et al. investigated the performance of bare (uncoated) LPG fibre sensors fabricated without any sensitive material for measurement of standard RI solutions and mixtures of methanol and ethanol [77]. Initially, they tested the sensor's performance using standard RI mixtures, but also measured the temperature dependence of the sensor and repeatability of their results. Having established the fundamental sensor response to RI and temperature, Keith et al. examined varying the solution composition from $100 \%$ methanol through 50/50 methanol/ethanol to $100 \%$ ethanol at a set temperature of $20{ }^{\circ} \mathrm{C}$. Variations in the measured wavelengths in solutions produced a relative standard deviation of only 0.046 and 0.029 percent for methanol and ethanol, respectively, indicating excellent repeatability. With this method, unknown combinations of mixtures may be precisely determined. The observed accuracy was in the $0.5-1 \%$ range but producing repeatable results was a major issue. Raikar et al. produced gratings on one end of a singlemode Ge-B co-doped photosensitive fibre using the phase mask technique and then etched the region where the gratings were formed for ethanol concentration measurement [78]. The sensor was characterised for ethanol concentration ranging from 0 to $50 \%$, where red wavelength shift was observed with increasing ethanol concentration and exhibited a sensitivity of $0.002 \mathrm{~nm} / \%$.

Alemohammad et al. proposed a femtosecond (FS) laser micromachining fabrication process to inscribe micro-grooves in the cladding of the optical fibre, thereby incorporating FBGs for effective coupling of the propagating core modes to the surrounding medium [42]. A microscope image showing the on-fibre fabricated structures is shown in Figure 11a. The 
prepared FBG sensors were immersed in solutions of $2.6 \%$ and $4.8 \%$ polyvinyl butyral (PVB) in ethanol for concentration measurement along with their thermal responses, for which reflection spectra are shown in Figure 11b. The findings demonstrated enhanced sensitivity to the concentration of the surrounding medium and these micromachined surface-modified FBG sensors may be used for simultaneous concentration and temperature sensing in chemical and biological liquids.

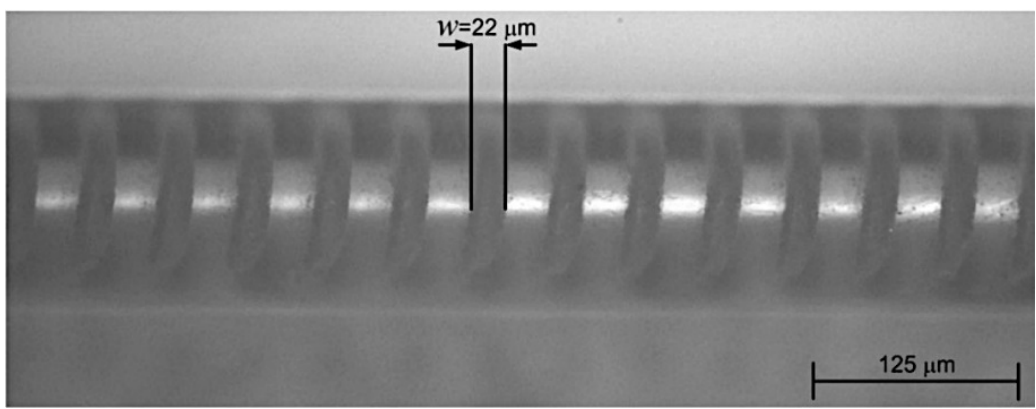

(a)

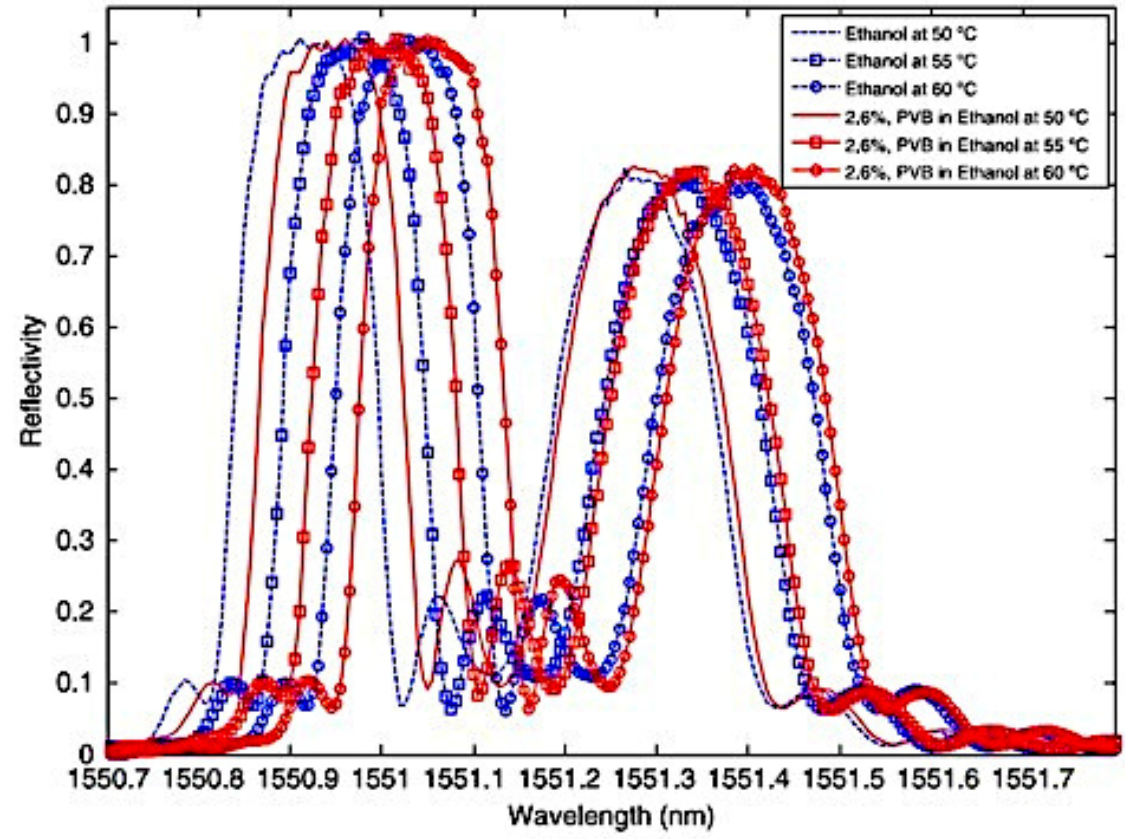

(b)

Figure 11. (a) Micro-grooved structure fabricated on the fibre. (b) Reflection spectra of micro-groovestructured FBG sensor for ethanol concentration and different concentrations of PVA in ethanol at different temperatures. Ref. [42]; (C IOP Publishing. Reproduced with permission. All rights reserved.

Possetti et al. investigated a refractometric sensor based on LPG fibres as a tool for the industrial sector of fuel mixtures or ethanol-gasoline blends [79]. Standard single-mode fibre SMF-28 was used for writing an LPG with a length of $21.6 \mathrm{~mm}$ and period of $540 \mu \mathrm{m}$. The sensor was tested for measuring ethanol in gasoline in concentrations ranging from 0 to $100 \%$ by introducing the samples into a glass cell. The LPG sensor indicated an average sensitivity of $43 \mathrm{pm} / \%$ for ethanol concentrations ranging from $20 \%$ to $40 \%$, which is the range of significance for the Brazilian industrial sector. The combined and expanded uncertainties for the LPG refractometric sensor were found to be smaller than those for an Abbe refractometer, which were $0.7 \%$ and $1.7 \%$, respectively. The same group later proposed an encapsulated LPG version for better device stability, protection from external damage and reproducibility of the LPG fabrication during multiple production cycles [80]. The encapsulation device comprised a quartz tube and a steel shield and was deemed 
to have minimal effect on LPG sensitivity. Both systems had a sensitivity of $10 \mathrm{~nm} / \mathrm{RIU}$ for aqueous ethanol solutions with RIs ranging from 1.33 to 1.36 , while samples with RIs ranging from 1.42 to 1.44 (gasoline, turpentine and kerosene) indicated a sensitivity of $102 \mathrm{~nm} /$ RIU. The authors concluded that it significantly improved the standard deviation in results, being as good as $58 \%$ for ethanol and $78 \%$ for gasoline, as compared to the non-encapsulated version [79].

The performance of an etched FBG constructed in various configurations to function as a refractometric sensor was analysed, for water-ethanol mixtures ranging from 0 to $100 \%$, by Coradin et al. [81]. Two wet-etched FBGs with Bragg wavelengths close to $1300 \mathrm{~nm}$ and $1500 \mathrm{~nm}$ were used and showed sensitivities of $6.5 \pm 0.2 \mathrm{~nm} / \mathrm{RIU}$ and $2.9 \pm 0.2 \mathrm{~nm} / \mathrm{RIU}$ at $25.0 \pm 0.5^{\circ} \mathrm{C}$, respectively. They also investigated the effect of the ambiguous relationship between RI and ethanol content in a mixture above a concentration of $80 \% v / v$. The sensor setup, based on the etched FBG1300, had a greater RI sensitivity compared to the FBG1500 version and showed combined uncertainties of $2.8 \% v / v$ and $7 \% v / v$ below and above the $80 \% v / v$ of ethanol concentration, respectively. Arasu et al. investigated an absorbance-based FBG ethanol sensor by coating thin films of gold of various thickness on clad FBGs [82]. They compared the absorbance responses of standard uncoated SMF, coated SMF, uncoated FBG and coated FBG. Sensors were coated with $35 \mathrm{~nm}, 40 \mathrm{~nm}$ and $50 \mathrm{~nm}$ thin gold films and it was observed that increasing the thickness of the gold layer increased the absorbance of sensor. Sensors were characterised for ethanol-water mixtures for ethanol concentrations ranging from 0 to $99.7 \%$. FBG sensors with $50 \mathrm{~nm}$ gold coating demonstrated good repeatability and higher sensitivity. The response and recovery time were observed to be approximately 20 and 35 s, respectively.

An optical sensing method based on a combination of an FBG and an LPG coated with cuprous oxide $\left(\mathrm{Cu}_{2} \mathrm{O}\right)$ was reported by Monteiro-Silva et al., where the LPG was used for ethanol quantification in ethanol-gasoline mixtures and the FBG was used for monitoring temperature [37]. They incorporated a PMMA-based flow cell for handling the sample in and out flow as well as providing access for the light input and output fibres of the two sensing probes as illustrated in Figure 12. The authors included results for spectra of the LPG probe when operated in air, pure ethanol, pure gasoline (no ethanol) and ethanol-gasoline mixtures of 1.5 to $30 \%$. A Cuprous oxide-coated LPG indicated a higher sensitivity of $0.76 \pm 0.01 \mathrm{~nm} / \% v / v$ (wavelength shift response) and $0.125 \pm 0.003 \mathrm{~dB} / \%$ $v / v$ (power attenuation response) for ethanol concentration ranging from $1.5 \% v / v$ to $30 \%$ $v / v$ in ethanol-gasoline mixtures in comparison to uncoated LPGs. The resulting resolution was determined as $5.1 \times 10^{-4}$ RIU and the authors state this optical fibre sensing system provided good performance whilst avoiding the use of expensive gas chromatography techniques to determine the ethanol-gasoline sample compositions [37]. Bui et al. presented a novel optical sensor design based on dual FBGs integrated in an erbium-doped fibre ring laser structure for measuring wavelength shift without the need for a spectrometer as a detector [83]. They used one FBG as a reference and an etched FBG as a sensing probe. The principle was based on the reference FBG sweeping over the entire spectrum of the etched FBG. This sensor design demonstrated identification of $0-14 \% v / v$ mixing ratios of ethanol and/or methanol in gasoline RON 92 (research octane number) with potentially high repeatability, accuracy, quick response and a limit of detection of $1.5 \times 10^{-4}$ RIU. They also experimented for nitrate-water samples. This design therefore demonstrated high potential as an inexpensive biochemical sensing method. 


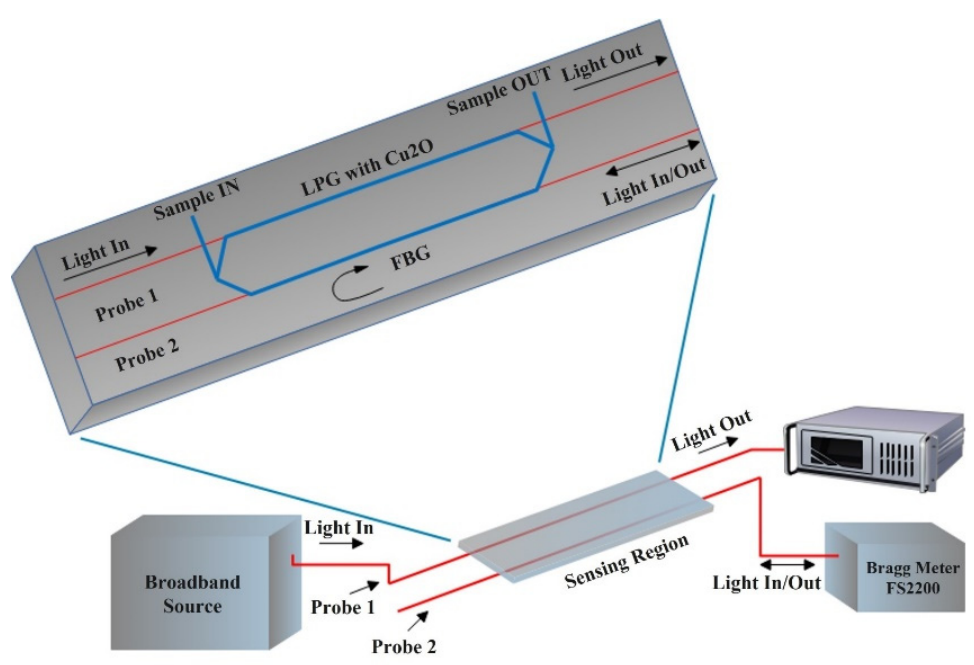

Figure 12. Cuprous oxide-coated LPG- and FBG-based optical fibre sensing setup with a PMMAbased flow cell for sample inflow and outflow. Adapted from Ref. [37].

Aristilde et al. investigated a tilted FBG (TFBG) for measurement of gasoline-adulteration avoiding the need for additional fibre etching when using FBGs [84]. The sensor measured ethanol concentration in gasoline-ethanol solutions using the convoluted response of two Bragg gratings as input for a TFBG. They interrogated responses of ethanol concentration from 0 to $60 \%$ in gasoline using two OSAs and photodetectors where the cladding modes were accessed to measure the change in RI surrounding the TFBG and the core modes were interrogated for temperature variations. It was estimated that the sensor can detect ethanol concentration changes of $1.5 \%$ in gasoline-ethanol mixtures and distinguish temperature variations of $0.5^{\circ} \mathrm{C}$. Kumar et al. recently utilised a GO-coated Etched FBG (EFBG) sensor for ethanol measurement in petrol [85]. When compared to an un-coated EFBG, the GOcoated etched FBG (EFBG) demonstrated a ten-fold increase in ethanol sensitivity. This sensor was based on measurement of changes in the intensity of the reflection spectra as the percentage of ethanol in petrol was varied from 0 to $100 \%$. The ethanol proportion in the fuel was detected down to $0.5 \%$, which was stated as being better than the standard EFBG-based purely on wavelength shift measurements. This sensor design exhibited a sensitivity of $0.18 \mathrm{~dB} /$ percent concentration and negligible temperature sensitivity within $5{ }^{\circ} \mathrm{C}$ of the external environment's value.

The sensors discussed in this section have been used for general and gasoline quality monitoring applications. It has been observed that FBGs are not inherently sensitive to chemical changes in the surrounding environment and require etching or a reduction in the cladding to become sensitive to surrounding ethanol changes. This makes them fragile and less robust, and temperature cross-sensitivity is a matter of concern. However, different configurations such as tilted FBGs can make them sensitive to the surrounding RI whilst maintaining a robust structure. On the contrary, LPGs do not require etching or deformation of the fibre and provide good sensing resolution. LPGs are inherently sensitive to temperature changes, but some compensation methods have been successfully deployed to overcome this, e.g., using a combined LPG and FBG sensing scheme. Grating sensors often require costly interrogation systems such as spectrum analysers or spectrometers. This obstacle can be mitigated, e.g., using a dual FBG interrogation scheme [83], which may be helpful for developing a future low-cost ethanol sensing system.

The different configurations of grating sensors including LPGs, FBGs, EFBGs, TFBG, Dual FBGs, Metal-coated FBGs and Micro-grooved FBGs are illustrated in Table 4 which summarises the various configurations in terms of the system attributes, sensor physi$\mathrm{cal} /$ geometrical considerations (e.g., coating type), and their intended application area, sensitivity $(\mathrm{S})$, resolution $(\mathrm{R})$ and measurement range. 
Table 4. Summary of fibre grating optical fibre ethanol sensors.

\begin{tabular}{|c|c|c|c|c|c|c|c|c|}
\hline Sensor Design & Fibre Type & $\begin{array}{l}\text { Sensitive } \\
\text { Coating }\end{array}$ & $\begin{array}{l}\text { Light Sources } \\
\text { and Detectors }\end{array}$ & $S^{*}$ & $\mathbf{R}^{* *}$ & $\begin{array}{c}\text { Measurement } \\
\text { Range }\end{array}$ & Application & Ref. \\
\hline LPG & Bare LPG & None & - & - & - & $\begin{array}{l}0-100 \% \\
\text { ethanol in } \\
\text { methanol }\end{array}$ & General & [77] \\
\hline Etched FBG & $\begin{array}{c}\text { Singlemode Ge-B } \\
\text { co-doped } \\
\text { photosensitive fibre } \\
\text { (Newport F- SBG } \\
-15 \text { and cladding } \\
\text { diameter } \\
125 \pm 1 \mu \mathrm{m})\end{array}$ & None & $\begin{array}{l}\text { Broadband Light } \\
\text { source and } \\
\text { Optical } \\
\text { Spectrum } \\
\text { Analyser (OSA) }\end{array}$ & $0.002 \mathrm{~nm} / \%$ & - & $0-50 \%$ & General & [78] \\
\hline $\begin{array}{c}\text { Microgrooved } \\
\text { FBG }\end{array}$ & $\begin{array}{c}\text { SMF } \\
(125 \mu \mathrm{m} \text { cladding } \\
\text { diameter }) \text { with } \\
\text { FBG of } 22 \mu \mathrm{m} \\
\text { period }\end{array}$ & None & $\begin{array}{c}\text { FBG } \\
\text { Interrogating } \\
\text { System }\end{array}$ & - & - & $\begin{array}{c}\text { Ethanol and } \\
2.6 \% \text { and } 4.8 \% \\
\text { PVB in ethanol }\end{array}$ & General & [42] \\
\hline LPG & $\begin{array}{c}\text { SMF-28 } \\
\text { with } 21.6 \mathrm{~mm} \text { long } \\
\text { LPG of } \\
540 \mu \mathrm{m} \text { period }\end{array}$ & None & $\begin{array}{c}\text { Super- } \\
\text { Luminescent } \\
\text { LED and OSA }\end{array}$ & $43 \mathrm{pm} / \%$ & - & $20-40 \%$ & $\begin{array}{l}\text { Monitoring of } \\
\text { ethanol- } \\
\text { gasoline } \\
\text { blends }\end{array}$ & [79] \\
\hline $\begin{array}{c}\text { Encapsulated } \\
\text { LPG }\end{array}$ & $\begin{array}{c}\text { SMF-28 } \\
\text { with } 2.6 \mathrm{~cm} \text { long } \\
\text { LPG of } \\
400 \mu \mathrm{m} \text { period }\end{array}$ & None & $\begin{array}{l}\text { Broadband LED } \\
\text { with centre } \\
\text { wavelength of } \\
1550 \mathrm{~nm} \text { and } \\
\text { OSA }\end{array}$ & $\begin{array}{c}\text { Magnitude of } \\
10 \mathrm{~nm} / \mathrm{RIU} \\
\text { and } \\
0.013 \mathrm{~nm} / \%\end{array}$ & - & $\begin{array}{l}\text { Linear results } \\
\text { in } 0-70 \% \text { for } \\
\text { ethanol-water } \\
\text { mixtures }\end{array}$ & $\begin{array}{l}\text { Ethanol-water } \\
\text { and gasoline }\end{array}$ & [80] \\
\hline Etched FBG & $\begin{array}{c}\text { Standard SMF } \\
\text { based FBG1300 } \\
(\text { Central } \\
\text { Wavelength } \\
\text { CW }=1308.49 \mathrm{~nm}) \\
\text { and FBG1500 } \\
(\mathrm{CW}=1539.87 \mathrm{~nm}) \\
\text { with pitch of } \\
902.5 \mathrm{~nm} \text { and } \\
1062.5 \mathrm{~nm}, \\
\text { respectively }\end{array}$ & None & $\begin{array}{c}\text { LED1 (Superlum, } \\
\text { Pilot2, } \\
\text { CW = } 1544.2 \mathrm{~nm} \text { ), } \\
\text { LED2 (Superlum, } \\
\text { BroadLighter } \\
\text { S-1300-G-I-20 } \\
\text { SM) and OSA } \\
\text { (Anritsu, } \\
\text { MS9710B) }\end{array}$ & $\begin{array}{c}6.5 \pm \\
0.2 \mathrm{~nm} / \mathrm{RIU} \\
(\mathrm{FBG} 1300) \text { and } \\
2.9 \pm \\
0.2 \mathrm{~nm} / \mathrm{RIU} \\
\text { (FBG1500) }\end{array}$ & - & $\begin{array}{l}0-100 \% \text { for } \\
\text { ethanol-water } \\
\text { mixtures }\end{array}$ & General & [81] \\
\hline $\begin{array}{l}\text { Gold-coated } \\
\text { FBG }\end{array}$ & $\begin{array}{c}\text { Standard SMF and } \\
\text { Commercial SMF } \\
\text { FBG }\end{array}$ & Thin gold film & $\begin{array}{c}\text { Halogen white } \\
\text { light source } \\
\text { (HL2000) and } \\
\text { Ocean Optics } \\
\text { Spectrophotome- } \\
\text { ter } \\
\text { (USB4000) }\end{array}$ & $\begin{array}{c}2 \% \text { change in } \\
\text { absorbance } \\
\text { per } 10 \% \\
\text { change in } \\
\text { ethanol } \\
\text { concentration } \\
\sim 0.2(\Delta \mathrm{A} / \Delta \mathrm{C})\end{array}$ & - & $\begin{array}{l}0 \text { to } 99.7 \% \\
\text { ethanol in } \\
\text { water }\end{array}$ & General & [82] \\
\hline LPG and FBG & SMF 28 & $\begin{array}{l}\text { Cuprous oxide } \\
(\mathrm{Cu} 2 \mathrm{O})\end{array}$ & $\begin{array}{l}\text { SLD, Broadband } \\
\text { Source, OSA } \\
\text { (AQ 6315B) and } \\
\text { BraggMeter } \\
\text { FS2200 SA }\end{array}$ & $\begin{array}{c}0.76 \pm \\
0.01 \mathrm{~nm} / \% \\
v / v \text { and } 0.125 \\
\pm 0.003 \mathrm{~dB} / \% \\
v / v\end{array}$ & - & $\begin{array}{l}1.5 \% v / v \text { to } \\
30 \% v / v \\
\text { ethanol in } \\
\text { Gasoline }\end{array}$ & $\begin{array}{l}\text { Quantification } \\
\text { of ethanol- } \\
\text { gasoline } \\
\text { blends }\end{array}$ & [37] \\
\hline $\begin{array}{l}\text { Dual FBGs } \\
\text { integrated in } \\
\text { fibre ring laser } \\
\text { structure }\end{array}$ & SMF 28 for FBG & None & $\begin{array}{c}\text { Broadband light } \\
\text { source and OSA } \\
\text { (Advantest } \\
\text { Q8384) }\end{array}$ & - & $1.5 \times 10^{-4} \mathrm{RIU}$ & $\begin{array}{c}0-14 \% v / v \\
\text { ethanol in } \\
\text { gasoline RON }\end{array}$ & General & [83] \\
\hline Tilted FBG & $\begin{array}{c}\text { FBGs and Tilted } \\
\text { FBG with tilt angle } \\
\text { of } 6^{\circ}\end{array}$ & None & $\begin{array}{l}\text { SLD, OSA and } \\
\text { Photodetectors }\end{array}$ & - & $1.5 \%$ & $\begin{array}{l}0-60 \% \text { ethanol } \\
\text { in gasoline }\end{array}$ & $\begin{array}{l}\text { Gasoline } \\
\text { quality } \\
\text { monitoring }\end{array}$ & [84] \\
\hline Etched FBG & $\begin{array}{l}\text { Singlemode Ge-B } \\
\text { co-doped } \\
\text { photo-sensitive } \\
\text { fibre (Fibre Core } \\
\text { PS1250/150; } \\
\text { cladding diameter } \\
\sim 125 \mu \mathrm{m} \text { ) }\end{array}$ & $\begin{array}{c}\text { Graphene } \\
\text { oxide (GO) }\end{array}$ & $\begin{array}{l}\text { Broadband ASE } \\
\text { source and OSA } \\
\text { (JDSU, MTS8000) }\end{array}$ & $\begin{array}{c}0.18 \\
\mathrm{~dB} / \text { percent }\end{array}$ & - & $\begin{array}{l}0-100 \% \\
\text { ethanol in } \\
\text { petrol }\end{array}$ & $\begin{array}{c}\text { Ethanol } \\
\text { detection in } \\
\text { petrol }\end{array}$ & [85] \\
\hline
\end{tabular}

* Sensitivity, ${ }^{* *}$ resolution.

\subsection{Plasmonic Sensors}

Plasmonic optical fibre sensors are based on the Surface Plasmon Resonance (SPR) phenomenon and occurs at a resonance wavelength of the incident light on a metal-dielectric interface due to the collective oscillation of conduction band electrons. This happens due to the excitation of electrons in the metal surface layer by the photons of incident light with a specific angle of incidence. These electrons then travel parallel to the metal surface creating 
a wave pattern called as Surface Plasmon Wave (SPW) or Surface Plasmon Polaritons (SPPs), as shown in Figure 13.
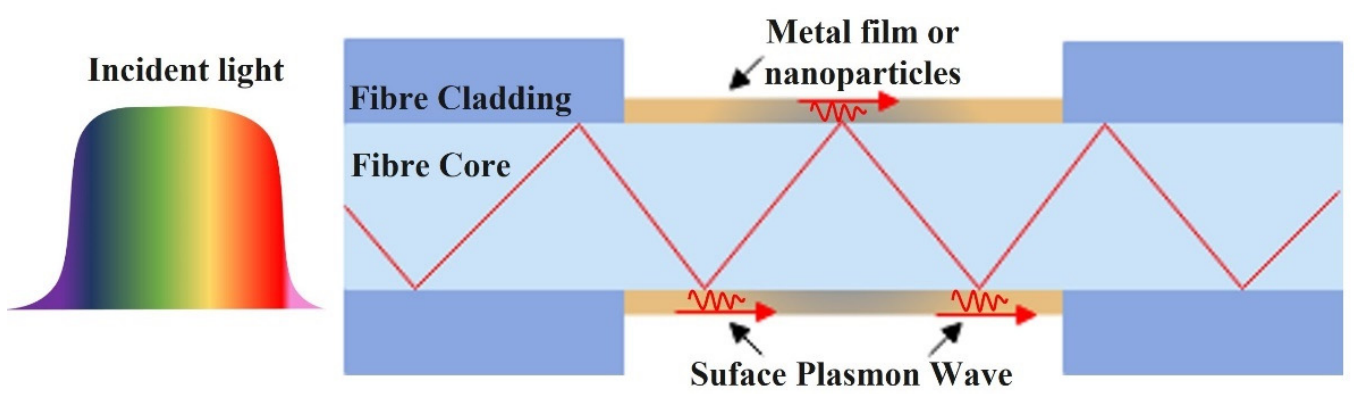

Transmitted light

Figure 13. Schematic diagram of plasmonic optical fibre sensor.

Many highly sensitive SPR sensors have been proposed for biochemical analyte testing. Fibre-based plasmonic sensors have drawn growing interest in comparison to classic prismbased plasmonic sensors due to their merits for online monitoring, small size, efficient integration and remote measurement. When light propagates through the fibre core, TIR occurs at the fibre-metal interface which generates an evanescent field as explained earlier in Section 2.1. The wave vector of the evanescent wave is given by [86]:

$$
k_{E V}=\frac{\omega}{c} \sqrt{\varepsilon_{0}} \sin \theta
$$

where $\varepsilon_{o}$ is the dielectric constant of the cladding or core (if the cladding is removed) of the optical fibre, $\theta$ is angle of incidence of the light and $\omega$ represents the angular frequency of the incident light. The surface plasmon wave vector propagating along the metal-dielectric interface is given by [86]:

$$
k_{S P}=\frac{\omega}{c}\left(\frac{\varepsilon_{m} \varepsilon_{s}}{\varepsilon_{m}+\varepsilon_{s}}\right)^{1 / 2}
$$

where $\varepsilon_{m}$ and $\varepsilon_{S}$ are the dielectric constants of the metal and dielectric medium, respectively. The surface plasmon resonance occurs when $k_{E V}$ matches with the real part of $k_{S P}$.

The fibre surface plasmon may be divided into two categories based on the plasmon mode of transmission: SPR and localised surface plasmon resonance (LSPR). SPR is created by coating a thin metal film on the surface of an optical fibre and the resonance condition that occurs at a specific wavelength generates SPR, leading to a dip/attenuation in the spectrum at the resonance wavelength. LSPR is created by coating metal nanoparticles on the fibre and when the incoming light frequency resonates with the entire vibrational frequency of the conducting electrons in the metal nanoparticles. The light energy is significantly absorbed at this frequency (wavelength) [87]. SPR and LSPR resonant wavelengths change when the surrounding RI of the metal layer changes.

In 1999, Mitsushio et al. proposed an unclad gold-coated optical fibre sensor system for ethanol and ethylene glycol sensing [88]. The results demonstrated the sensor to be capable of operation in the concentration range of 0 to $80 \%$ of ethanol in water with a limit of detection of $0.5 \%$. The same sensor was also tested for alcohol content in commercial liquor (Shochu), which indicated good agreement with the labelled ethanol content of $25 \% v / v$ on the bottle. As it is one of the first systems developed for such sensor designs, they used a $632.8 \mathrm{~nm}$ He-Ne laser source (Melles Griot V05LHR15) and a discrete lens to illuminate the input of the fibre. These limitations have been improved over the years for SPR sensing systems. A cone micro-tip shaped SPR device was investigated for ethanol and methanol concentration measurement by Kurihara et al. [89]. The sensing technique relied on a polarization rotation in the presence of SPR using $780 \mathrm{~nm}$ light obtained from a chopped laser source. They created the cone shape on the step-index optical fibre of a $\mathrm{GeO}_{2}$ highly doped silica core using a chemical etching process, which took two hours at 
room temperature. A gold metal film was then deposited on the cone shape and a groove was subsequently created on the gold metal film by manually scratching using a small screwdriver. The gold film was deposited across the entire end-face of the fibre and was nominally 50-nm thick, but the thickness was estimated to decrease to $13 \mathrm{~nm}$ on the tip due to varied deposition and the conical geometry of the tip. The sensor demonstrated a limited resolution of $10^{-2}$ RIU.

In 2005, Suzuki et al. proposed a dual-colour optical fibre SPR sensor by depositing a silver layer at the fibre tip to create a mirror as well as depositing a gold layer on the surface of the core of a step index silica MMF of $400 \mu \mathrm{m}$ core diameter [90]. The sensor's working principle was based on a differential reflectance method. Two optical couplers provided source light from two light emitting diodes (LEDs) of $612 \mathrm{~nm}$ and $680 \mathrm{~nm}$ that were pulsed alternately in a continuous cycle to the sensor section. The RI changes of ethanol-water solutions ranging from 0 to $50 \%$ (1.333 to 1.3616) were observed as being proportional to changes in reflectance at the two wavelengths. The sensor was estimated to have an LOD of $5.2 \times 10^{-4}$ RIU. The possibility of using excitation of SPP was studied by Abrahamyan et al. [91]. They used the tip of a gold-coated conical-shaped optical fibre to measure ethanol concentrations in specific solutions when the tip was dipped in the medium with a particular dielectric permittivity. They performed experiments on a dimethyl sulfoxide and ethanol solution with volume ratio of 0.9 . The dielectric permittivity of the solution varied gradually because of evaporation and a corresponding change in the output radiation from the fibre tip was observed as per resonant excitation of SPPs. This sensor design formed the concept for novel optical fibre SPR sensors for chemical sensing with comparable sensitivity to the conventional SPR sensors, i.e., $2 \times 10^{-4}$ RIU.

Mitsushio et al. reported a basic SPR sensor system by depositing a $45 \mathrm{~nm}$ Au-film on one half of the core of a MM glass optical fibre and fixing the sensor element and Teflon tubes for fluidic guiding (in and out) of the samples in a glass tube [92]. They investigated the use of different wavelength LEDs (563 nm, $660 \mathrm{~nm}$ and $940 \mathrm{~nm}$ ) to determine the performance of the SPR sensor system. The output intensity versus RI response curves showed dips at different refractive indices for different incident wavelengths, which is indicative of a dependence on the system performance on the source wavelength. The same authors experimented with ethanol solutions in the range of 0 to $50 \%$ by volume (\% ABV) concentration using a $660 \mathrm{~nm}$ red LED light source at $15^{\circ} \mathrm{C}$ and produced calibration curves showing resolution comparable to an Abbe refractometer, i.e., $10^{-4}$ RIU. The calibration curves were used for analysis of measurements on ethanol concentration in eight commercial spirits, where reasonable agreement was observed between the measured and the labelled ethanol content in the spirits. Zhang et al. presented a new approach for surface modification of a tapered optical fibre using star-shaped gold nano particles of 80 to $120 \mathrm{~nm}$ in size [40]. They compared two different coupling agents to self-assemble the nano particles, namely: 3aminopropyltrimethoxy silane (APTMS) and 3-mercaptopropyltrimethoxy silane (MPTMS). A comparison of the transmission spectra of the MPTMS modified fibres revealed a greater sensitivity than the APTMS modified fibres. To demonstrate the sensitivity of the modified fibres, transmission spectra were measured for ethanol and gentian violet solutions. They treated the APTMS and MPTMS modified fibres with t-dodecylmercaptan and observed that APTMS modified fibres became less sensitive to different surrounding media. They further characterised MPTMS modified fibres for ethanol concentrations ranging from $10 \%$ to $40 \%$; they showed wavelength and intensity shifts in the spectrum and the sensor indicated a sensitivity of $1190.5 \mathrm{~nm} / \mathrm{RIU}$ [40]. Hlubina et al. demonstrated two SPR RI sensing configurations, i.e., inline transmission and reflection operating over a wavelength range of 500 to $800 \mathrm{~nm}$ provided by a tungsten-halogen broadband light source [93]. They sputtered a $50 \mathrm{~nm}$ gold film on both sides of different lengths of unclad multimode fibres for both configurations. In both experimental setups, polarisers were used for transmission configuration which demonstrated the polarization dependence of this scheme. The inclusion of polarisers produced a deep spectral dip. Both sensor configurations were tested for ethanol concentrations ranging from 0 to $80 \mathrm{wt} . \%$ and, thus, demonstrated a 
wavelength shift with increasing ethanol concentration. The reflection sensing scheme resulted in higher sensitivity but also non-linearity at higher concentrations of ethanol. In comparison, the inline transmission configuration, including the polariser, presented lower sensitivity with a more linear response over the range of ethanol concentration changes.

Verma et al. investigated an SPR sensing method combined with functionalization using ethanol-selective enzymes for low ethanol concentration in food and beverages [94]. They first coated the fibre core with $40 \mathrm{~nm}$ of silver (Ag) and then immobilised the enzymes using a gel entrapment method. Two different sensor probes were prepared by immobilising the alcohol dehydrogenase (ADH) enzyme only and ADH enzyme with nicotinic acid. The observed resonance wavelength shift for 0 to $10 \mathrm{mM}$ of ethanol concentration in buffer solution was $7.00 \mathrm{~nm}$ and $18.33 \mathrm{~nm}$ for the $\mathrm{Ag} / \mathrm{ADH}$ and Ag/ADH/Nicotinic acid probes, respectively. This corresponded to the higher observed sensitivity of the $\mathrm{Ag} / \mathrm{ADH} / \mathrm{Nicotinic}$ acid probe. These sensors were also investigated for their stability, reusability and reproducibility and produced a good response in each case. It was observed that sensors have good sensitivity for low ethanol concentrations as it decreased for higher ethanol concentrations, where the ethanol concentrations ranged from 0 to $10 \mathrm{mM}$. In follow-up work, a silver/silicon/hydrogel entrapped with ADH-/NAD-coated unclad optical fibre for ethanol sensing was investigated [95]. The sensor was found to be sensitive to ethanol concentration in the range of $0-5 \mathrm{mM}$ with a maximum sensitivity of $21.70 \mathrm{~nm} / \mathrm{mM}$. It was observed that the co-enzyme used in this configuration increased the sensitivity by almost 33\%.

Muri et al. demonstrated a low-finesse Fabry-Perot cavity using a hydrogel half-sphere mounted on the fibre end face also coated with gold nanoparticles (GNP) and, therefore, combined interferometry and LSPR [72]. The free spectral range (FSR) and LSPR, resulting from the degree of swelling of the hydrogel while increasing the ethanol concentration from $30 \%$ to $50 \%$, were measured. This paper was previously discussed in Section 2.2. of this article on interferometric sensors.

Sun et al. coupled a curved D-shaped optical fibre sensor with a microfluidic device for sensing bio-liquids with various RIs [38]. Multimode optical fibres were polished into a D-shape using the curvature trench method by embedding the fibre on a glass substrate. Then, a gold film of 10-12 nm was sputtered on the fibre-embedded glass substrate. A micro-fluidic chip was created using laser ablation to form patterns on a PMMA substrate and double-sided tape was used to secure the inlet and outlet ports of the fluid channel. The double-sided tape was subsequently used to bond to the D-shaped gold-coated optical fibre sensor for integration. The sensor was used to detect ethanol, methanol, ethanolmethanol and glucose solutions and the authors claim to have achieved a general maximum sensitivity of $10^{-5}$ RIU and $3.12 \times 10^{-5}$ RIU specifically for ethanol. This corresponded to a minimum detectable limit of $0.06 \%\left(6 \times 10^{-4}\right)$ or $600 \mathrm{ppm}$ ethanol. The integrated microfluidic chip achieved small size, low sample consumption and in-vivo measurement. The design of the microfluidic chip, experimental setup and SPR resonance spectra for ethanol measurement are shown in Figure 14 [38]. Jiang et al. proposed a novel U-bent POF LSPR sensor based on a graphene $(G)$ and silver nanoparticles (AgNPs) structure [96]. A POF with $1 \mathrm{~mm}$ diameter was bent into a U-shape and a thin discontinuous layer of silver (Ag) was deposited on it. The thin layer of Ag was then coated with PVA (Polyvinyl alcohol)/G/AgNPs mixture by dip coating. They investigated different inner diameters of U-POF and thicknesses of Ag film for ethanol solution measurement in the range of 1.330 to 1.3657 RIU. The maximum sensitivity was measured as $700 \mathrm{~nm} / \mathrm{RIU}$. It was also observed that graphene improved the sensitivity of the LSPR sensor and delayed the oxidation process of the AgNPs [96], which causes aging of the sensor. 


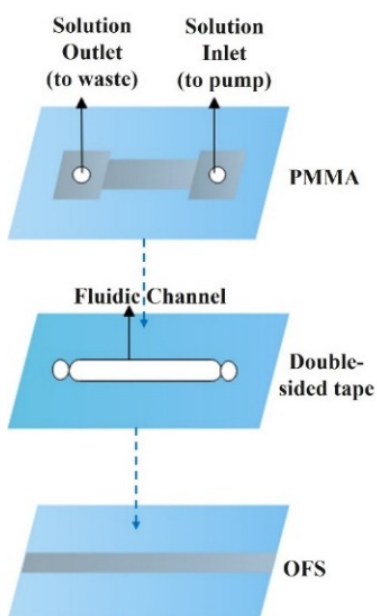

(a)

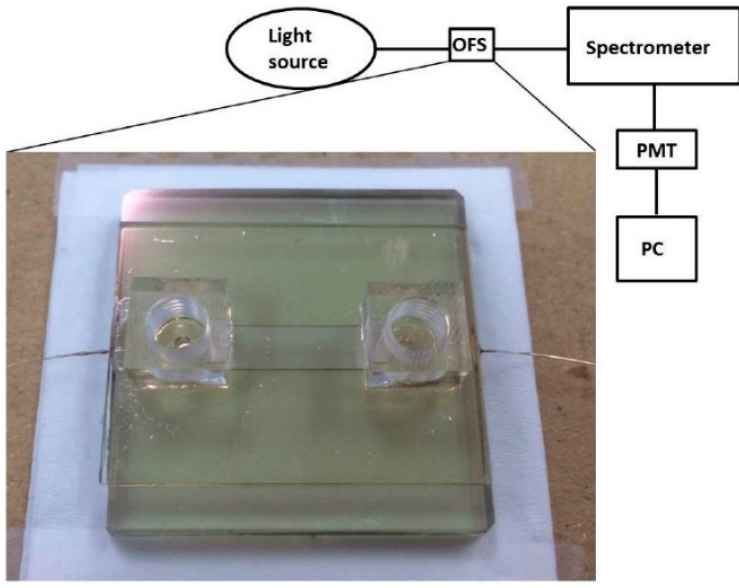

(b)

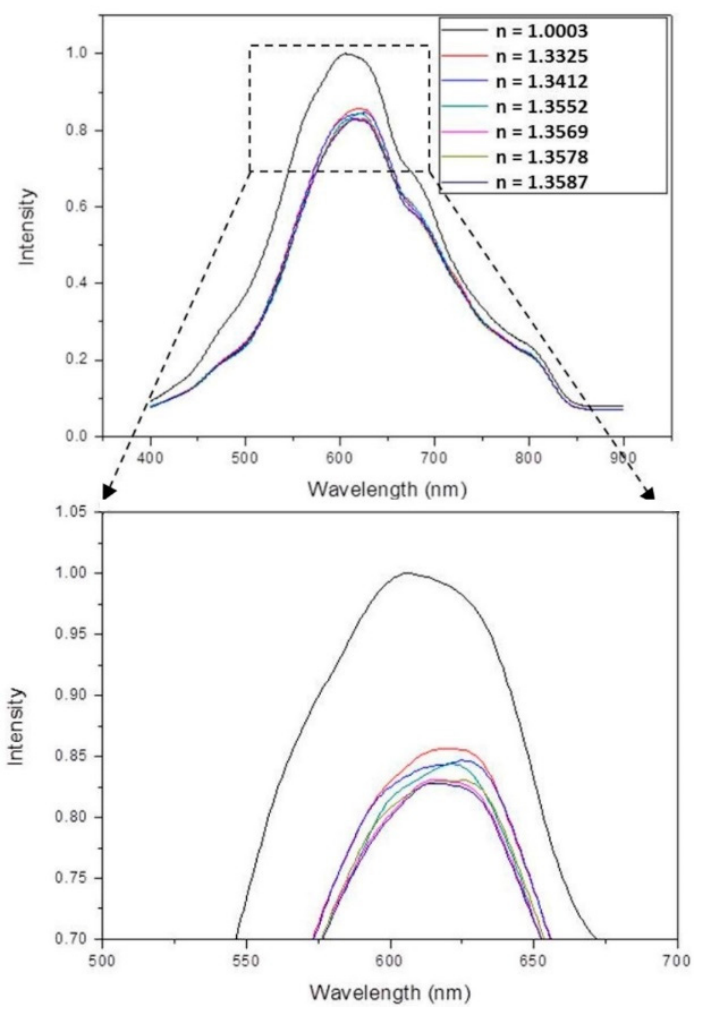

(c)

Figure 14. (a) Schematic representation of the microfluidic chip structure. (b) Experimental setup and photograph of the chip. (c) SPR resonance spectra for ethanol measurement. Reproduced from Ref. [38].

Sharma et al. investigated a samarium doped chalcogenide optical fibre used as an SPR sensor with a polymer cladding incorporating different coatings including an $\mathrm{MoS}_{2}$ base monolayer and a polythiophene (PT) layer coated over a 42-nm-thick Ag film for alcohols (ethanol + methanol) concentration measurement in water [97]. The sensor used an angular interrogation technique or selective ray (on-axis) method, which involved launching monochromatic light into the fibre core at different angles. This entailed mounting the laser diode light source on a rotary stage in order to launch the input light at different angles. The NIR signal was measured as a power loss (in $\mathrm{dB}$ ) following transmission through the SPR interaction zone. The performance of the different configurations was compared quantitatively by formulating a figure of merit (FOM) for each one. The PT 
layer aided selectivity and allowed identification of the alcohols and provided an enhanced figure of merit (FOM). The authors claim significant improvement from previous work, i.e., 1647 FOM $\left(\mathrm{RIU}^{-1}\right)$ at $1200 \mathrm{~nm}$ wavelength. It was also discovered that laser sources with longer NIR wavelengths resulted in an improved FOM and detection limit for the sensor. However, the sensitivity at longer wavelengths was lower, although this was compensated by a considerably higher accuracy. Xi et al. utilised a D-shaped fibre SPR sensor coated with an Au nanofilm-graphene layer [39]. The intended use was to detect highly sensitive DNA hybridization, but they were able to assess the SPR performance of the sensor using ethanol solutions with RI values ranging from 1.3330 to 1.3657 RIU. The graphene was grown directly onto copper and then gold film was sputtered on it, which ensured a better contact between the gold and graphene layer. The Au-graphene structure was finalised by etching the copper foil away using an $\mathrm{FeCl}_{3}$ solution. This process is shown schematically in Figure 15. Figure 16 shows the experimental results obtained by varying the ethanol concentration in the range of 0 to $80 \%$, which gave rise to the RIU range specified above. The sensor produced a maximum red shift of $40 \mathrm{~nm}$ in the spectral dip minimum value over the range of concentration 0 to $80 \%$. The sensitivity resulting from these measurements was determined as $1223 \mathrm{~nm} / \mathrm{RIU}$.

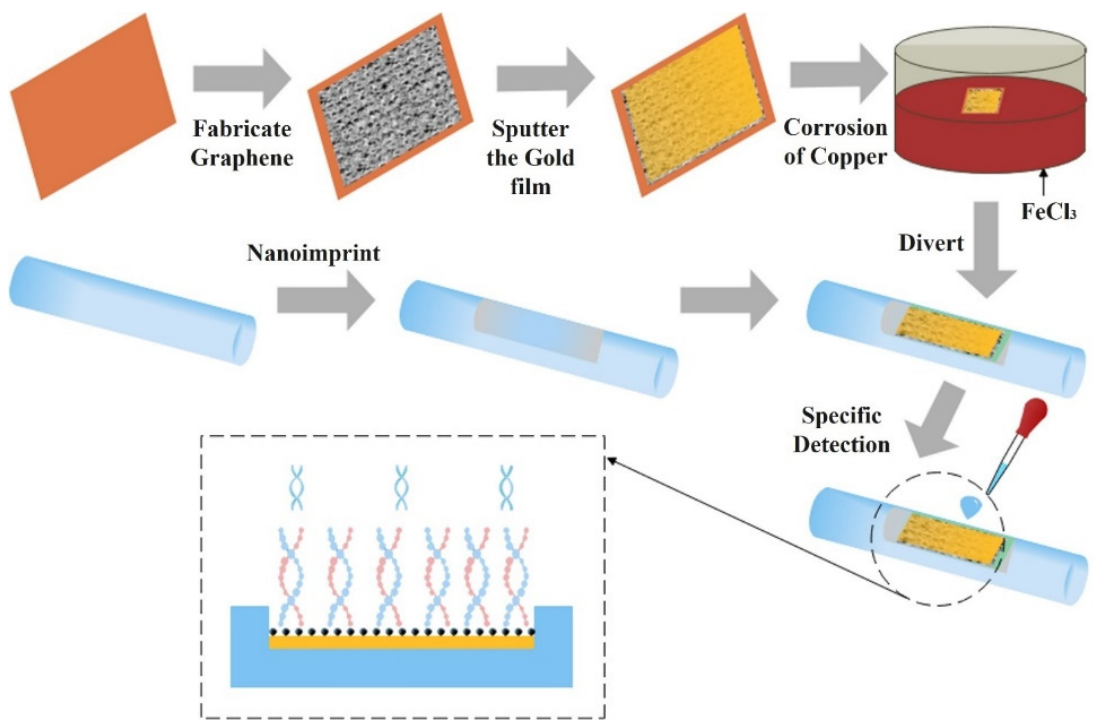

Figure 15. Preparation procedure of Au-graphene-based D-type fibre SPR sensor. Reproduced from Ref. [39].
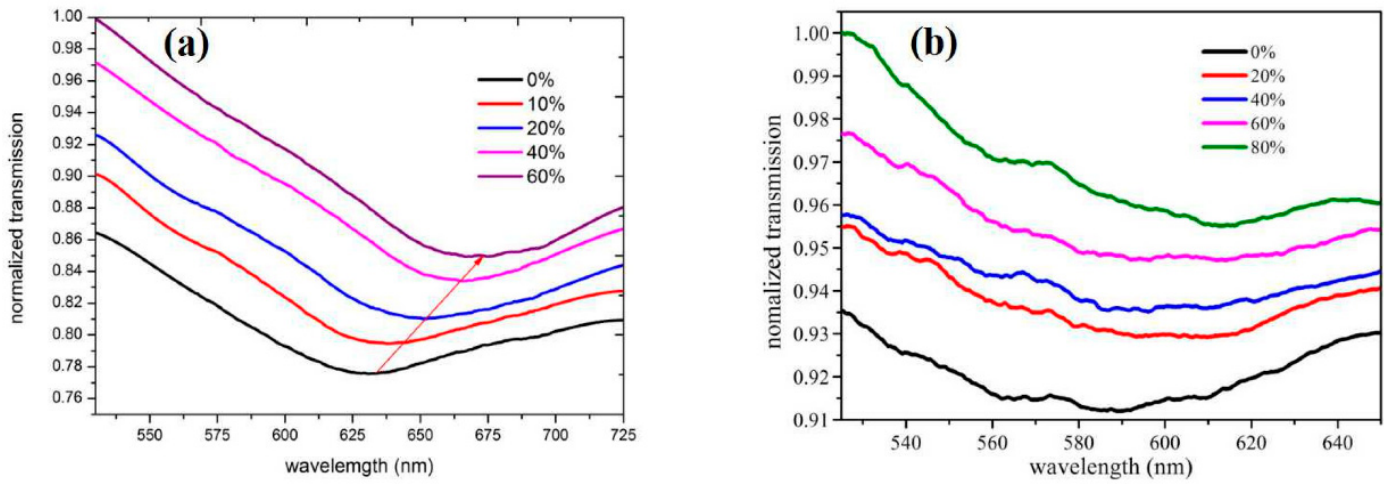

Figure 16. Transmission spectra of D-type fibre SPR sensor for different alcohol concentrations: (a) Au-graphene film-based, (b) gold film only. Reproduced from Ref. [39].

Guo et al. reported a novel lab-on-fibre approach for measuring RI to detect isopropyl alcohol, ethanol and methanol when they were applied separately on the sensor tip [98]. 
This lab-on-fibre sensor was designed by creating an array of nano cavities on the tip of a multimode optical fibre and then sputtering a $90-\mathrm{nm}$ thin gold film on the side walls of the fibre and on the residual photoresist layer of 30 to $40 \mathrm{~nm}$ after etching process on the fibre tip, thus creating a conical cross-section of gold nanohole array. The etching process was implemented using electron beam lithography. In the case of ethanol detection, the sensitivity was measured to be $653 \mathrm{~nm} /$ RIU at a wavelength of $812.5 \mathrm{~nm}$ when the solution was changed from pure methanol to pure ethanol. The same measurements showed response and recovery times of $0.96 \mathrm{~s}$ and $4.1 \mathrm{~s}$, respectively. It was demonstrated that both the conical cross-section of the gold nano-hole array and the underlying nano-cavities give rise to increased sensitivity.

It is clear that the SPR technique is capable of delivering accurate and highly sensitive optical fibre sensing solutions for ethanol concentration measurement. Recent advances in fabrication techniques have resulted in improved miniaturization which was exemplified in [98], where a lab-on-fibre ethanol sensor was reported. The combination of the progress in device and fabrication processes as well as significant improvements in computing capabilities for interpreting complex signals, e.g., spectral signatures using artificial intelligence techniques, means that there is significant potential for the incorporation of these techniques in future robust industrial measurement systems. However, some challenges remain particularly in achieving uniform and reliable thin metal coatings. The performance and various configurations of the Plasmonic Optical Fibre Ethanol sensors referenced above are further summarised in Table 5 in terms of sensor design, fibre type, metal coating, light sources and detectors, sensitivity (S), resolution (R), measurement range and type of application.

Table 5. Summary of plasmonic optical fibre ethanol sensors.

\begin{tabular}{|c|c|c|c|c|c|c|c|c|}
\hline Sensor Design & Fibre Type & Metal Coating & $\begin{array}{l}\text { Light Source and } \\
\text { Detector }\end{array}$ & $S^{*}$ & $\mathbf{R}^{* *}$ & $\begin{array}{l}\text { Measurement } \\
\text { Range }\end{array}$ & Application & Ref. \\
\hline $\begin{array}{l}\text { Gold-coated } \\
\text { unclad } \\
\text { straight SPR } \\
\text { sensor in a } \\
\text { glass tube }\end{array}$ & $\begin{array}{l}\text { NJ-PF200/300 } \\
(200 \mu \mathrm{m} \text { core } \\
\text { diameter and } \\
300 \mu \mathrm{m} \text { clad } \\
\text { diameter })\end{array}$ & Gold film & $\begin{array}{l}\text { 632.8 } \mathrm{nm} \text { He-Ne Laser } \\
\text { (Melles Griot } \\
\text { V05LHR15), } 50 \mathrm{~cm} \text { focal } \\
\text { length lens and ILX } \\
\text { Lightwave } \\
\text { (VOMM-6722B) }\end{array}$ & - & - & $\begin{array}{c}\text { 0-80\% } \\
\text { LOD: } 0.5 \%\end{array}$ & $\begin{array}{l}\text { Ethanol } \\
\text { content in } \\
\text { liquor }\end{array}$ & [88] \\
\hline $\begin{array}{l}\text { Gold-coated } \\
\text { cone-shaped } \\
\text { SPR } \\
\text { microdevice }\end{array}$ & $\begin{array}{l}\text { Single-mode } \\
\text { GeO2 doped } \\
\text { silica core fibre }\end{array}$ & $\begin{array}{l}\text { Gold film } \\
(13 \mathrm{~nm})\end{array}$ & $\begin{array}{c}\text { Chopped Laser Source } \\
\text { (780 nm) and } \\
\text { Photodetector }\end{array}$ & - & $10^{-2} \mathrm{RIU}$ & - & General & [89] \\
\hline $\begin{array}{l}\text { Dual-colour } \\
\text { SPR sensor }\end{array}$ & $\begin{array}{l}\text { Step index } \\
\text { multimode } \\
\text { fibre }(400 \mu \mathrm{m} \\
\text { core diameter })\end{array}$ & $\begin{array}{l}\text { Silver and } \\
\text { gold film }(10 \\
\text { to } 70 \mathrm{~nm})\end{array}$ & $\begin{array}{l}\text { Tungsten halogen lamp, } \\
\text { LEDs }(612 \mathrm{~nm} \text { and } \\
680 \mathrm{~nm}) \text { and } \\
\text { Photodetector }\end{array}$ & - & - & $\begin{array}{c}\text { 0-50\% } \\
\text { LOD: } 5.2 \times \\
10^{-4} \text { RIU }\end{array}$ & General & [90] \\
\hline $\begin{array}{l}\text { Conical shape } \\
\text { SPR sensor }\end{array}$ & $\begin{array}{c}100 \mu \mathrm{m} \\
\text { diameter } \\
\text { optical fibre }\end{array}$ & $\begin{array}{l}\text { Gold film } \\
(50 \mathrm{~nm})\end{array}$ & $\begin{array}{l}\text { Semiconductor laser } \\
\text { (690 nm wavelength) } \\
\text { and PIN Photodiode }\end{array}$ & - & $2 \times 10^{-4} \mathrm{RIU}$ & $\begin{array}{l}0.9 \text { volume } \\
\text { ratio of } \\
\text { dimethyl } \\
\text { sulfoxide and } \\
\text { ethanol } \\
\text { solution }\end{array}$ & General & [91] \\
\hline $\begin{array}{l}\text { Gold-coated } \\
\text { straight SPR } \\
\text { sensor fixed in } \\
\text { a glass tube }\end{array}$ & $\begin{array}{l}\text { NJ-PF200/300 } \\
(200 \mu \mathrm{m} \text { core } \\
\text { diameter and } \\
300 \mu \mathrm{m} \text { clad } \\
\text { diameter })\end{array}$ & $\begin{array}{l}\text { Gold film } \\
(45 \mathrm{~nm})\end{array}$ & $\begin{array}{l}\text { LEDs }(563 \mathrm{~nm}, 660 \mathrm{~nm} \\
\text { and } 940 \mathrm{~nm} \text { ) and } \\
\text { Photodiode }\end{array}$ & - & $10^{-4}$ RIU & $0-50 \%$ & $\begin{array}{l}\text { Ethanol } \\
\text { content in } \\
\text { spirits }\end{array}$ & [92] \\
\hline $\begin{array}{l}\text { Tapered fibre } \\
\text { LSPR sensor }\end{array}$ & $\begin{array}{l}\text { Single-mode } \\
\text { optical fibre } \\
\text { (SMF28e) }\end{array}$ & $\begin{array}{l}\text { Star-shaped } \\
\text { gold nano } \\
\text { particles }(80 \text { to } \\
120 \mathrm{~nm})\end{array}$ & $\begin{array}{c}\text { Bromine tungsten light } \\
\text { source (BFC-445), } \\
\text { Monochromator } \\
\text { (SBP500), Side window } \\
\text { detector } \\
\text { photomultiplier } \\
\text { (PMTH-S1) }\end{array}$ & $1190.5 \mathrm{~nm} / \mathrm{RIU}$ & - & $10-40 \%$ & General & [40] \\
\hline
\end{tabular}


Table 5. Cont.

\begin{tabular}{|c|c|c|c|c|c|c|c|c|}
\hline Sensor Design & Fibre Type & Metal Coating & $\begin{array}{l}\text { Light Source and } \\
\text { Detector }\end{array}$ & $S^{*}$ & $\mathbf{R} * *$ & $\begin{array}{l}\text { Measurement } \\
\text { Range }\end{array}$ & Application & Ref. \\
\hline $\begin{array}{l}\text { Double-sided metal } \\
\text { sputtered SPR sensor } \\
\text { (inline } \\
\text { transmission-based } \\
\text { scheme and } \\
\text { reflection-based } \\
\text { scheme) }\end{array}$ & $\begin{array}{l}\text { Polymer-clad- } \\
\text { silica (PCS) } \\
\text { multimode } \\
\text { optical fibre } \\
\text { (core diameter } \\
\text { of } 200 \mu \mathrm{m} \text { ) }\end{array}$ & $\begin{array}{l}\text { Thin gold film } \\
(50 \mathrm{~nm}), \mathrm{ADH} \\
\text { and } \\
\text { ADH/Nicotinic } \\
\text { acid }\end{array}$ & $\begin{array}{l}\text { Halogen lamp (Ocean } \\
\text { Optics HL2000) and } \\
\text { Spectrometer (Ocean } \\
\text { Optics USB4000) }\end{array}$ & - & - & $0-80 \%$ & General & [93] \\
\hline $\begin{array}{l}\text { Silver-coated SPR } \\
\text { sensor combined } \\
\text { with ADH and } \\
\text { ADH/nicotinic acid } \\
\text { enzymes }\end{array}$ & $\begin{array}{l}\text { PCS fibre (core } \\
\text { diameter of } \\
600 \mu \mathrm{m})\end{array}$ & $\begin{array}{l}\text { Thin silver } \\
\text { film }(40 \mathrm{~nm})\end{array}$ & $\begin{array}{l}\text { AvaLight-HAL } \\
\text { tungsten halogen lamp, } \\
\text { Microscope objective } \\
\text { and UV-VIS-NIR } \\
\text { Avaspec-3648 optical } \\
\text { fibre spectrometer }\end{array}$ & - & - & $0-10 \mathrm{mM}$ & $\begin{array}{l}\text { Ethanol in } \\
\text { food and } \\
\text { beverages }\end{array}$ & [94] \\
\hline $\begin{array}{l}\text { Silver/silicon/hydrogel } \\
\text { layered SPR sensor } \\
\text { with ADH and } \\
\text { ADH/nicotinic acid } \\
\text { enzymes }\end{array}$ & $\begin{array}{l}\text { PCS fibre (core } \\
\text { diameter of } \\
600 \mu \mathrm{m})\end{array}$ & $\begin{array}{l}\text { Thin silver } \\
\text { film }(40 \mathrm{~nm}) \\
\text { and Silicon } \\
(8 \mathrm{~nm})\end{array}$ & $\begin{array}{l}\text { Tungsten halogen lamp, } \\
\text { Microscope objective } \\
\text { and UV-VIS-NIR } \\
\text { Avaspec-3648 optical } \\
\text { fibre spectrometer }\end{array}$ & $21.70 \mathrm{nM} / \mathrm{mM}$ & - & $0-5 \mathrm{mM}$ & General & [95] \\
\hline $\begin{array}{c}\text { FPI-based LSPR } \\
\text { sensor }\end{array}$ & $\begin{array}{c}\text { Double- } \\
\text { Cladded } \\
\text { Optical Fibre } \\
\text { (DCOF) } \\
\text { (DCF13, } \\
\text { Thorlabs) }\end{array}$ & $\begin{array}{c}\text { Gold } \\
\text { Nanoparticles } \\
(\text { GNP) }\end{array}$ & $\begin{array}{c}\text { Light Sources (MBB1F1, } \\
470-850 \mathrm{~nm} \text { and } \\
\text { S5FC1005S, 1550 nm } \\
\text { Thorlabs) and } \\
\text { Spectrometers } \\
\text { (QE65Pro and } \\
\text { NIRQuest-512-1.7 } \\
\text { Ocean Optics) }\end{array}$ & - & - & $30-50 \%$ & General & [72] \\
\hline $\begin{array}{c}\text { Curved D-type SPR } \\
\text { sensor integrated } \\
\text { with microfluidic } \\
\text { chip }\end{array}$ & $\begin{array}{l}\text { Multimode } \\
\text { fibre } \\
\text { (core diameter } \\
\text { of } 62.5 \mu \mathrm{m} \\
\text { and cladding } \\
\text { diameter of } \\
125 \mu \mathrm{m} \text { ) }\end{array}$ & Gold thin film & $\begin{array}{c}\text { Tungsten halogen lamp } \\
\text { (LS-1, Ocean Optics), } \\
\text { Photoluminescence } \\
\text { spectrometer (Triax 320) } \\
\text { and Photomultiplier } \\
\text { (R5108, Hamamatsu } \\
\text { Photonics)3. }\end{array}$ & $\begin{array}{c}3.12 \times 10^{-5} \\
\text { RIU }^{1}\end{array}$ & - & $\begin{array}{l}\text { LOD: } 0.06 \% \text { or } \\
\quad 600 \mathrm{ppm}\end{array}$ & General & [38] \\
\hline $\begin{array}{l}\text { U-bent LSPR sensor } \\
\text { based on a graphene } \\
(G) \text { and silver } \\
\text { nanoparticles } \\
\text { (AgNPs) structure }\end{array}$ & $\begin{array}{l}\text { Plastic Optical } \\
\text { Fibre (POF) } \\
\text { with } 1 \mathrm{~mm} \\
\text { diameter }\end{array}$ & $\begin{array}{l}\text { PVA/G/AgNPs } \\
\text { @ Ag thin film } \\
(3,5,6,7 \text { and } \\
10 \mathrm{~nm})\end{array}$ & $\begin{array}{l}\text { Light source ( } 380 \mathrm{~nm} \text { to } \\
780 \mathrm{~nm} \text { ) and PG2000 } \\
\text { spectrometer } \\
\text { (Ideaoptics } \\
\text { Instruments) }\end{array}$ & $700 \mathrm{~nm} / \mathrm{RIU}$ & - & $1.330-1.3567$ & General & [96] \\
\hline $\begin{array}{l}\text { Samarium doped } \\
\text { chalcogenide optical } \\
\text { fibre SPR sensor } \\
\text { (Ag/MoS2 mono- } \\
\text { layer/perfluorinated } \\
\text { (PF) homopolymer } \\
\text { layer/polythiophene } \\
\text { (PT) layer) with } \\
\text { angular interrogation } \\
\text { technique }\end{array}$ & $\begin{array}{l}\text { Samarium } \\
\text { doped } \\
\text { chalcogenide } \\
\text { core/polymer } \\
\text { clad }\end{array}$ & $\begin{array}{c}\operatorname{Ag}(42 \mathrm{~nm}) \\
\text { MoS2 } \\
(0.71 \mathrm{~nm}) \\
\text { PT }(\sim 7 \mathrm{~nm})\end{array}$ & $\begin{array}{l}\text { Laser diode and } \\
\text { photodetector }\end{array}$ & $\begin{array}{l}177.18^{\circ} / \text { RIU } \\
\text { (for ethanol in } \\
\text { water) and } \\
182.821^{\circ} / \text { RIU } \\
\text { (for methanol } \\
\text { in water) }\end{array}$ & - & $\begin{array}{c}\text { Ethanol-water, } \\
\text { methanol-water } \\
\text { and ethanol- } \\
\text { methanol binary } \\
\text { mixtures } \\
\text { LOD: } 5.04 \times \\
10^{-6} \text { RIU (at } \\
\text { ethanol in water) } \\
\text { to } 4.8 \times 10^{-6} \\
\text { RIU (at methanol } \\
\text { in water) }\end{array}$ & General & [97] \\
\hline $\begin{array}{c}\text { Au } \\
\text { nanofilm-graphene } \\
\text { D-type SPR sensor }\end{array}$ & $\begin{array}{l}\text { POF }(1 \mathrm{~mm} \\
\text { diameter })\end{array}$ & $\begin{array}{l}\text { Au and } \\
\text { graphene }\end{array}$ & $\begin{array}{c}\text { Light source } \\
(380-78 \mathrm{~nm}) \text { and } \\
\text { spectrometer (PG2000) }\end{array}$ & 1223 nm/RIU & - & $\begin{array}{c}1.3330-1.3657 \\
\text { ethanol solutions }\end{array}$ & $\begin{array}{c}\text { Specificity } \\
\text { bioanalysis }\end{array}$ & [39] \\
\hline $\begin{array}{c}\text { Cavity-coupled } \\
\text { conical cross-section } \\
\text { gold nanohole array } \\
\text { LSPR sensor }\end{array}$ & $\begin{array}{l}\text { Multimode } \\
\text { optical fibre } \\
\text { (Corning } \\
\text { Infinicor SX + } \\
50 / 125 \text { ) (core } \\
\text { diameter of } \\
50 \mu \mathrm{m} \text { and } \\
\text { cladding } \\
\text { diameter of } \\
125 \mu \mathrm{m} \text { ) }\end{array}$ & $\begin{array}{l}\text { Photoresist } \\
(30-40 \mathrm{~nm}) \\
\mathrm{Au}(90 \mathrm{~nm})\end{array}$ & $\begin{array}{l}\text { Broadband halogen } \\
\text { light source and } \\
\text { spectrometer } \\
\text { (StellarNet, Inc.) }\end{array}$ & $653 \mathrm{~nm} / \mathrm{RIU}$ & - & - & RI sensing & [98] \\
\hline
\end{tabular}

${ }^{*}$ Sensitivity, ${ }^{* *}$ resolution, ${ }^{1}$ as defined by [38]

\section{Current Status and Future Prospects of Optical Fibre Ethanol Sensors}

The essential design parameters as well as the characteristics and the sensing performance of four major categories of optical fibre ethanol sensors, i.e., absorbance, interferometric, grating and plasmonic sensors, were described in detail and are summarised in Tables 2-5. Clearly, a broad variety of optical fibre ethanol sensors, based on unique structural configurations and sensitive coatings, have been reported and their efficacy has 
been verified experimentally in the literature. Fluorescence-based optical fibre sensors have also been reported in limited cases, including $[34,99,100]$. Recent developments in whispering gallery mode type sensors have also been reported for ethanol measurement in aqueous solutions for which resonant modes are supported and the light signal circulates in a dielectric ring or microbubble. The supported modes form the 'whispering gallery' modes, leading to an enhanced light interaction length in the surrounding medium of the bubble or ring, which facilitates high-sensitivity ethanol concentration measurement [101-104]. Although the WGM sensors are a relatively recent development and have shown great promise in terms of enhanced sensitivity, their widespread use in industrial measurement is limited by the fact that the sharp (high Q) spectral resonance peak needs to be monitored using a high-resolution OSA or similar instrument.

The diversity of sensor designs and configurations of optical fibre ethanol sensors is summarised in Table 6 and includes a summary of the advantages and disadvantages of the four main sensor categories considered in this review.

Table 6. Summary of advantages and disadvantages of four main categories of optical fibre ethanol sensors.

\begin{tabular}{|c|c|c|}
\hline Sensor Type & Advantages & Disadvantages \\
\hline Absorption-based sensors & $\begin{array}{c}\text { Easy, simple, versatile and low-cost design. } \\
\text { Ease of implementation. } \\
\text { Reproducibility. }\end{array}$ & $\begin{array}{l}\text { Fragility due to deformation of fibre. } \\
\text { Low selectivity without a sensitive film. }\end{array}$ \\
\hline Interferometric sensors & $\begin{array}{l}\text { Robust and easily implemented. } \\
\text { Multimode Interferometers: Easy design, } \\
\text { flexible structure and reproducible. } \\
\text { Sensitive. }\end{array}$ & $\begin{array}{l}\text { Costly, precise and delicate design procedures for } \\
\text { most interferometric techniques. } \\
\text { Multimode Interferometers: non-periodic spectrum } \\
\text { and, hence, difficult signal demodulation. } \\
\text { Hydrogel-based FPI: difficult reproducibility. }\end{array}$ \\
\hline Fibre grating sensors & $\begin{array}{c}\text { Adjustable structure design. } \\
\text { FBG and LPG: When combined, can be } \\
\text { used for simultaneous temperature and RI } \\
\text { measurement. }\end{array}$ & $\begin{array}{l}\text { Require expensive interrogation systems. } \\
\text { FBG: Fragile due to fibre etching for RI measurements } \\
\text { and temperature crosstalk. } \\
\text { LPG: Complicated signal demodulation. }\end{array}$ \\
\hline Plasmonic sensors & $\begin{array}{l}\text { Accuracy. } \\
\text { High sensitivity. }\end{array}$ & $\begin{array}{l}\text { High processing requirements in terms of uniformity } \\
\text { and thickness consistency of metal coating. }\end{array}$ \\
\hline
\end{tabular}

It is clear that optical fibre ethanol sensors have undergone remarkable development in recent decades in terms of sensing performance, robust design and miniaturization. A number of optical fibre sensors have shown great potential for ethanol concentration measurement in a wide range of real-world applications. This is based primarily on their characteristics, including potential low fabrication cost, small size, design flexibility, immunity to external electromagnetic interference and capability for long-distance sensing (from the point of measurement). Current research is mainly focused on making compact and flexible sensor structures using the wide range of different designs and available fibres as well as continuously striving to improve sensing performance using various sensitive materials such as novel 2D materials, new metal nano-films and nanoparticles and deformation (e.g., etching or tapering) of the fibre. However, this can often make sensor processing and fabrication complex and, in some cases, compromises the mechanical strength required for many industrial applications. Maintaining the uniformity and thickness of metal films and other coatings requires accurate processing with excellent repeatability. The repeatability is particularly significant in cases where novel 2D materials are used in combination with metal coatings to improve sensitivity. The coating process is often necessarily complex to achieve better contact between the metal and a functionalised sensitive layer. Crosssensitivity to temperature and other chemicals in solutions containing ethanol is also a matter of concern as it can affect the selectivity and accuracy. Based on current developments and the perceived requirements of industrial applications, particularly with the arrival of Industry 4.0 and its relation to the burgeoning developments in the context of IoT, 
the following have been identified as significant future directions for research in optical fibre-based ethanol concentration sensors:

1. Targeting specific applications is crucial in bringing the technology to a real-world implementation. Being a good target analyte, it is necessary to explore and realise the application-specific requirements where ethanol concentration measurement is an important parameter, e.g., in biofuel production and processing, general fuel monitoring, the food and beverage industry, the paints and varnishes industry, medical diagnostics, and in the cosmetics industry. A specific example is evident in the case of bio-ethanol production using biomasses, specifically algae. There are very stringent requirements for specific sensitivity and resolution attainment, temperature stability and selectivity for sensing purposes as well as the ability to operate in real-time, which are crucial to avoiding sample loss and long lead time offline analysis [41,62]. It is clear that optical fibre sensors have a significant role to play in providing solutions in this scenario.

2. In many cases of industrial production and/or processing, high-sensitivity/ultralow-level ethanol sensing is a fundamental requirement. Hence, many researchers have focused on improving the sensitivity of optical fibre ethanol sensors by seeking improvements in materials, coatings as well as sensor structures. However, temperature cross-sensitivity and/or cross-sensitivity caused by other chemical species in the measurand solution are also significant issues. Some researchers have formulated techniques to mitigate temperature cross-sensitivity, including an inline C-shaped open-cavity FPI [68], a combination of FP cavity and Michelson interferometry [69], micro grooved FBG [42], a combination of FBG and LPG for simultaneous temperature and RI measurement [37] and etched FBGs [84]. Cross-sensitivity due to other chemicals can be minimised or avoided by improving the selectivity of sensors and some work has also been reported for improving selectivity by modifying POF with CNTs [56], by combining interferometric and LSPR techniques [72] and by using ethanol-selective enzymes [94]. However, these sensor systems exhibit other drawbacks such as the use of specialised essential non-commercial parts, complex interrogation methods, low mechanical strength, narrow measurement range and limited sample-by-sample measurement. It is important to state here that some of those drawbacks may be irrelevant for some applications, depending on their specific requirements. Therefore, future research is likely to be focused on achieving high sensitivity combined with high selectivity and temperature compensation of optical fibre ethanol sensors.

3. Reusability of optical fibre ethanol sensors, specifically when they are coated with novel 2D materials and/or precious metals, is becoming increasingly important. In the case of SPR chemical sensors, some reusability techniques are explored such as removing the immobilised histidine-tagged peptide (HP) layer using imidazole (IM) on Ni metal to regenerate the sensor surface [105], by cutting and polishing the sensor tip to regenerate the surface [106] and by exposing the sensor to ethanol for repeated cycles [107] to demonstrate the reproducibility of results.

4. Distributed optical fibre sensing techniques for industrial measurement have gained significant attention during the last 10 years, which has culminated in many commercial systems becoming available (e.g., Luna [108] and OZ Optics [109]). Distributed optical fibre sensors are currently being used in several industrial applications, e.g., in oil and gas exploration, and in large structure monitoring. This technology certainly has scope for future measurements covering large scale ethanol industrial production and other chemical processing applications [110]. However, interrogation of distributed optical fibre sensors is complex and the instrumentation is currently expensive. Consequently, their uses are currently confined to a few 'high end' applications, e.g., where very large numbers of sensing points are required and non-optical measurement is not feasible. Research in this direction in combination with real-time, robust, sensitive and selective optical fibre ethanol sensing can help realise the Indus- 
try 4.0 requirements of real-time sensing and data collection to develop a digital twin of the facilities to predict yield and future demands of ethanol in industrial production and processing.

All these future directions and requirements of optical fibre ethanol sensors in the current industrial framework are interconnected. Knowing specific application needs can enhance the understanding of optical fibre ethanol sensor manufacturing techniques such as specific requirements for sensitivity, robustness, reusability, temperature limitations and coating materials and, hence, the industrial requirements for real time and remote sensing. Figure 17 explains the interconnection between the application requirements, sensor design, manufacturing techniques and the current industrial framework.

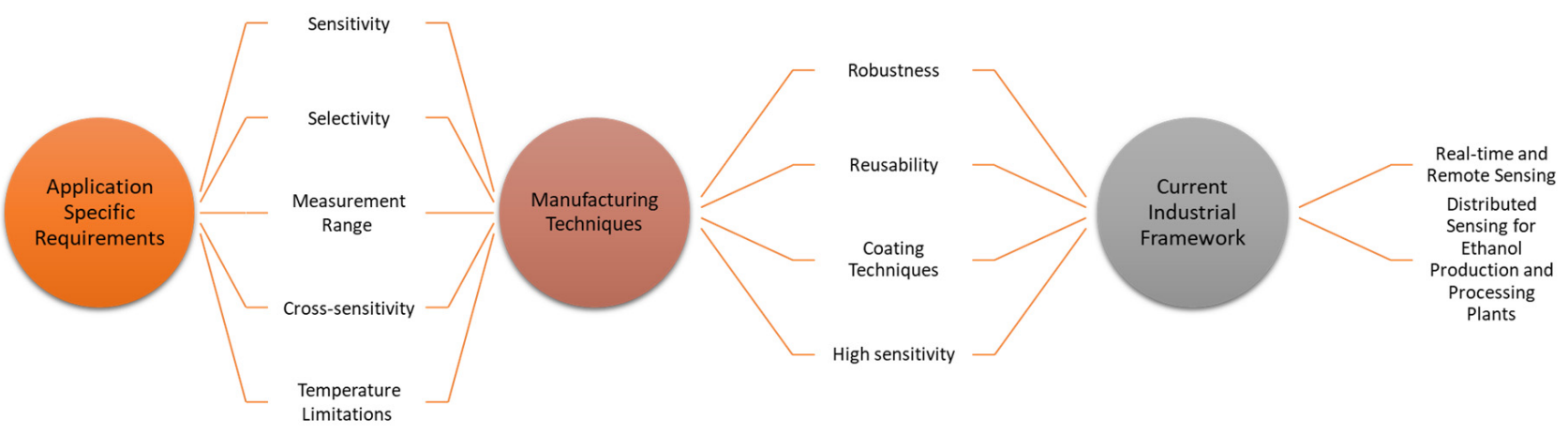

Figure 17. Interconnection of application-specific requirements, manufacturing techniques and the current industrial framework.

\section{Conclusions}

The four main optical fibre ethanol sensing techniques and their characteristics were discussed and summarised, i.e., absorbance, interferometric, fibre grating and plasmonic sensing, in terms of design parameters, fibre types, light sources and detectors, sensitive films/coatings, sensitivity, resolution, measurement ranges and applications. The advantages and disadvantages of all the types of optical fibre ethanol concentration sensors were also discussed with future potential research possibilities outlined. Enhancement of the sensitivity, selectivity, cross-sensitivity compensation and simplicity of manufacturing techniques can act as a driver for further improvement in optical fibre ethanol sensors, ensuring their advancement especially in the context of the specific modern-day industrial and technological needs.

Research progress shows that optical fibre ethanol sensors have the potential to be applied in broader industrially significant fields including biofuel production and processing, general fuel monitoring, food and beverages, paints and varnishes, medical diagnostics and cosmetics. High sensitivity, high selectivity and low cross-sensitivity are essential characteristics for implementation in real practical applications. In the future, the exploration of new structures and materials will intensify, but will remain subject to satisfaction of the above three performance indicators. Moreover, the current functionalization and biolayer deposition process of the majority of existing optical ethanol sensors are complex and the sensors are difficult to reuse. Therefore, the investigation of enhanced reusability may emerge as a significant research direction in the case of optical fibre ethanol sensors. Additionally, the growth in demand for multipoint and/or distributed sensing techniques for optical fibre ethanol sensors is likely to be a driver for the proliferation of these systems, particularly if the cost of interrogation is reduced through greater volume production and/or advancements in component technologies. The outlook for optical fibre-based ethanol sensing is, therefore, very strong in terms of both continued future research development as well as their likely penetration into growing industrial markets. 


\begin{abstract}
Author Contributions: Conceptualization, S.F.M. and E.L.; methodology, S.F.M.; investigation, S.F.M. and E.L.; resources, S.F.M. and E.L.; writing-original draft preparation, S.F.M.; writing-review and editing, S.F.M., E.L., R.W., B.S. and J.T.P.; Reassessment and revision of the article, B.S.C.; supervision, E.L., J.T.P. and B.S.C. All authors have read and agreed to the published version of the manuscript.

Funding: This research was funded by the European Union Erasmus Mundus INTACT Program; the Postgraduate Research Residential Scholarship by Plasssey Campus Centre, University of Limerick, Ireland; the Electronic and Computer Engineering Department, University of Limerick, Ireland; the Science Foundation Ireland, SFI/12/RC/2302_P2; and, in part, by the China Scholarship Council (CSC). The authors would also like to acknowledge funding from the University of Limerick's programme for Covid-19 Related Research Costed Extensions, which was supported by the Higher Education Authority and the Government of Ireland Department of Further and Higher Education, Research, Innovation and Science.
\end{abstract}

Institutional Review Board Statement: Not applicable.

Informed Consent Statement: Not applicable.

Data Availability Statement: Not applicable.

Acknowledgments: This work was supported by the Optical Fibre Sensors Research Centre, University of Limerick, Ireland.

Conflicts of Interest: The authors declare no conflict of interest.

\title{
References
}

1. Ethanol Uses, Benefits, and Chemical Safety Facts. Available online: https://www.chemicalsafetyfacts.org/ethanol/ (accessed on 25 April 2021).

2. Ethanol Explained-U.S. Energy Information Administration (EIA). Available online: https://www.eia.gov/energyexplained/ biofuels/ethanol.php (accessed on 25 April 2021).

3. Beverage \& Industrial Use-EPURE. Available online: https:/ / www.epure.org/about-ethanol/beverage-industrial-use/ (accessed on 25 April 2021).

4. Onuki, S.; Koziel, J.A.; Jenks, W.S.; Cai, L.; Grewell, D.; van Leeuwen, J.H. Taking Ethanol Quality beyond Fuel Grade: A Review. J. Inst. Brew. 2016, 122, 588-598. [CrossRef]

5. Tharsika, T.; Thanihaichelvan, M.; Haseeb, A.S.M.A.; Akbar, S.A. Highly Sensitive and Selective Ethanol Sensor Based on ZnO Nanorod on SnO2 Thin Film Fabricated by Spray Pyrolysis. Front. Mater. 2019, 6, 122. [CrossRef]

6. Fernanbes, E.N.; Reis, B.F. Automatic Flow Procedure for the Determination of Ethanol in Wine Exploiting Multicommutation and Enzymatic Reaction with Detection by Chemiluminescence. J. AOAC Int. 2004, 87, 920-926. [CrossRef]

7. Numata, Y.; Shinohara, Y.; Tanaka, H. Quantitative Analysis of Ethanol-Methanol-Water Ternary Solutions Using Raman Spectroscopy. Spectrosc. Lett. 2019, 52, 306-311. [CrossRef]

8. Castritius, S.; Kron, A.; Schäfer, T.; Rädle, M.; Harms, D. Determination of Alcohol and Extract Concentration in Beer Samples Using a Combined Method of Near-Infrared (NIR) Spectroscopy and Refractometry. J. Agric. Food Chem. 2010, 58, 12634-12641. [CrossRef]

9. Seo, H.B.; Kim, H.J.; Lee, O.K.; Ha, J.H.; Lee, H.Y.; Jung, K.H. Measurement of Ethanol Concentration Using Solvent Extraction and Dichromate Oxidation and Its Application to Bioethanol Production Process. J. Ind. Microbiol. Biotechnol. 2009, 36, $285-292$. [CrossRef]

10. Weatherly, C.A.; Woods, R.M.; Armstrong, D.W. Rapid Analysis of Ethanol and Water in Commercial Products Using Ionic Liquid Capillary Gas Chromatography with Thermal Conductivity Detection and/or Barrier Discharge Ionization Detection. J. Agric. Food Chem. 2014, 62, 1832-1838. [CrossRef]

11. Castellari, M.; Sartini, E.; Spinabelli, U.; Riponi, C.; Galassi, S. Determination of Carboxylic Acids, Carbohydrates, Glycerol, Ethanol, and 5-HMF in Beer by High-Performance Liquid Chromatography and UV-Refractive Index Double Detection. J. Chromatogr. Sci. 2001, 39, 235-238. [CrossRef]

12. Brereton, P.; Hasnip, S.; Bertrand, A.; Wittkowski, R.; Guillou, C. Analytical Methods for the Determination of Spirit Drinks. TrAC-Trends Anal. Chem. 2003, 22, 19-25. [CrossRef]

13. Collins, T.S.; Miller, C.A.; Altria, K.D.; Waterhouse, A.L. Development of a Rapid Method for the Analysis of Ethanol in Wines Using Capillary Electrophoresis. Am. J. Enol. Vitic. 1997, 48, 280-284.

14. Sumbhate, S.; Sumbhate, S.V.; Nayak, S.; Goupale, D.; Tiwari, A.; Jadon, R.S. Colorimetric Method for the Estimation of Ethanol in Alcoholic-Drinks. J. Anal. Tech. 2012, 1, 1-6.

15. Bennett, C. Spectrophotometric Acid Dichromate Method for the Determination of Ethyl Alcohol. Am. J. Med. Technol. 1971, 37, 217-220. [PubMed]

16. Pilone, G. Determination of Ethanol in Wine by Titrimetric and Spectrophotometric Dichromate Method: Collaborative Study. J Assoc. Off. Anal. Chem. 1985, 68, 188-190. [CrossRef] [PubMed] 
17. Osorio, D.; Pérez-Correa, J.R.; Agosin, E.; Cabrera, M. Soft-Sensor for on-Line Estimation of Ethanol Concentrations in Wine Stills. J. Food Eng. 2008, 87, 571-577. [CrossRef]

18. Sanford, C.L.; Mantooth, B.A.; Jones, B.T. Determination of Ethanol in Alcohol Samples Using a Modular Raman Spectrometer. J Chem. Educ. 2001, 78, 1221-1225. [CrossRef]

19. Advantages and Disadvantages of Raman Spectroscopy-Romanian Database of Raman Spectroscopy. Available online: http: / / www.rdrs.ro/blog/articles/advantages-disadvantages-raman-spectroscopy/ (accessed on 8 January 2022).

20. Wang, M.L.; Choong, Y.M.; Su, N.W.; Lee, M.H. A Rapid Method for Determination of Ethanol in Alcoholic Beverages Using Capillary Gas Chromatography. J. Food Drug Anal. 2003, 11, 133-140. [CrossRef]

21. Gerogiannaki-Christopoulou, M.; Kyriakidis, N.v.; Athanasopoulos, P.E. New Refractive Index Method for Measurement of Alcoholic Strength of Small Volume Samples. J. AOAC Int. 2003, 86, 1232-1235. [CrossRef]

22. Disadvantages \& Advantages of an HPLC. Available online: https://sciencing.com/disadvantages-advantages-hplc-5911530 html (accessed on 6 May 2021).

23. Erfkamp, J.; Guenther, M.; Gerlach, G. Hydrogel-Based Sensors for Ethanol Detection in Alcoholic Beverages. Sensors 2019, 19, 1199. [CrossRef]

24. Dasgupta, A. Methods of Alcohol Measurement. In Alcohol, Drugs, Genes and the Clinical Laboratory; Academic Press: Cambridge, MA, USA, 2017; pp. 155-166. ISBN 978-0-12-805455-0.

25. Sriariyanun, M.; Mutrakulcharoen, P.; Tepaamorndech, S.; Cheenkachorn, K.; Rattanaporn, K. A Rapid Spectrophotometric Method for Quantitative Determination of Ethanol in Fermentation Products. Orient. J. Chem. 2019, 35, 744-750. [CrossRef]

26. Zhang, P.; Hai, H.; Sun, D.; Yuan, W.; Liu, W.; Ding, R.; Teng, M.; Ma, L.; Tian, J.; Chen, C. A High Throughput Method for Total Alcohol Determination in Fermentation Broths. BMC Biotechnol. 2019, 19, 30. [CrossRef]

27. Kuswandi, B.; Irmawati, T.; Hidayat, M.A.; Jayus; Ahmad, M. A Simple Visual Ethanol Biosensor Based on Alcohol Oxidase Immobilized onto Polyaniline Film for Halal Verification of Fermented Beverage Samples. Sensors 2014, 14, 2135-2149. [CrossRef] [PubMed]

28. Nowak, P.M.; Woźniakiewicz, M.; Gładysz, M.; Janus, M.; Kościelniak, P. Improving Repeatability of Capillary Electrophoresis-a Critical Comparison of Ten Different Capillary Inner Surfaces and Three Criteria of Peak Identification. Anal. Bioanal. Chem. 2017, 409, 4383-4393. [CrossRef] [PubMed]

29. Magr1' ', A.D.; Magrı'fabrizio, A.L.; Balestrieri, M.; Sacchini, A.; Marini, D. Spectrophotometric Micro-Method for the Determination of Ethanol in Commercial Beverages. Fresenius J. Anal. Chem. 1997, 357, 985-988. [CrossRef]

30. Zhang, Y.N.; Sun, Y.; Cai, L.; Gao, Y.; Cai, Y. Optical Fiber Sensors for Measurement of Heavy Metal Ion Concentration: A Review. Measurement 2020, 158, 107742. [CrossRef]

31. Yin, M.J.; Gu, B.; An, Q.F.; Yang, C.; Guan, Y.L.; Yong, K.T. Recent Development of Fiber-Optic Chemical Sensors and Biosensors: Mechanisms, Materials, Micro/Nano-Fabrications and Applications. Coord. Chem. Rev. 2018, 376, 348-392. [CrossRef]

32. McDonagh, C.; Burke, C.S.; MacCraith, B.D. Optical Chemical Sensors. Chem. Rev. 2008, 108, 400-422. [CrossRef]

33. Walters, B.S.; Nielsen, T.J.; Arnold, M.A. Fiber-Optic Biosensor for Ethanol, Based on an Internal Enzyme Concept. Talanta 1988, 35, 151-155. [CrossRef]

34. Wolfbeis, O.S.; Posch, H.E. A Fibre Optic Ethanol Biosensor. Fresenius Z. Anal. Chem. 1988, 332, 255-257. [CrossRef]

35. Girei, S.H.; Shabaneh, A.A.; Arasu, P.T.; Painam, S.; Yaacob, M.H. Tapered Multimode Fiber Sensor for Ethanol Sensing Application. In Proceedings of the 2013 IEEE 4th International Conference on Photonics (ICP), Melaka, Malaysia, 28-30 October 2013; pp. 275-277.

36. Tian, J.; Quan, M.; Jiao, Y.; Yao, Y.; Liang, W.; Huang, Y.Y.; Xu, Y.; Lee, R.K.; Yariv, A. Fast Response Fabry-Perot Interferometer Microfluidic Refractive Index Fiber Sensor Based on Concave-Core Photonic Crystal Fiber. Opt. Express 2016, 24 , $20132-20142$. [CrossRef]

37. Monteiro-Silva, F.; Santos, J.L.; Manuel, J.; Martins De Almeida, M.; Coelho, L. Quantification of Ethanol Concentration in Gasoline Using Cuprous Oxide Coated Long Period Fiber Gratings. IEEE Sens. J. 2018, 18, 1493-1500. [CrossRef]

38. Sun, Y.-S.; Li, C.-J.; Hsu, J.-C. Integration of Curved D-Type Optical Fiber Sensor with Microfluidic Chip. Sensors 2016, 17, 63. [CrossRef] [PubMed]

39. Xi, X.; Xu, J.; Li, S.; Song, J.; Yang, W.; Sun, Y.; Jiang, S.; Han, Y.; Fan, X. An Au Nanofilm-Graphene/D-Type Fiber Surface Plasmon Resonance Sensor for Highly Sensitive Specificity Bioanalysis. Sensors 2020, 20, 991. [CrossRef] [PubMed]

40. Zhang, Q.; Xue, C.; Yuan, Y.; Lee, J.; Sun, D.; Xiong, J. Fiber Surface Modification Technology for Fiber-Optic Localized Surface Plasmon Resonance Biosensors. Sensors 2012, 12, 2729-2741. [CrossRef]

41. Memon, S.F.; Ali, M.M.; Pembroke, J.T.; Chowdhry, B.S.; Lewis, E. Measurement of Ultralow Level Bioethanol Concentration for Production Using Evanescent Wave Based Optical Fiber Sensor. IEEE Trans. Instrum. Meas. 2018, 67, 780-788. [CrossRef]

42. Alemohammad, H.; Toyserkani, E.; Pinkerton, A.J. Femtosecond Laser Micromachining of Fibre Bragg Gratings for Simultaneous Measurement of Temperature and Concentration of Liquids. J. Phys. D Appl. Phys. 2008, 41, 185101. [CrossRef]

43. Liao, C.; Zhu, F.; Zhou, P.; Wang, Y.; Kong, H. Fiber Taper-Based Mach-Zehnder Interferometer for Ethanol Concentration Measurement. Micromachines 2019, 10, 741. [CrossRef] [PubMed]

44. Wang, X.D.; Wolfbeis, O.S. Fiber-Optic Chemical Sensors and Biosensors (2013-2015). Anal. Chem. 2016, 88, 203-227. [CrossRef]

45. Wolfbeis, O.S. Fiber-Optic Chemical Sensors and Biosensors. Anal. Chem. 2004, 76, 3269-3284. [CrossRef]

46. Wolfbeis, O.S. Fiber-Optic Chemical Sensors and Biosensors. Anal. Chem. 2002, 74, 2663-2677. [CrossRef] 
47. Wang, X.D.; Wolfbeis, O.S. Fiber-Optic Chemical Sensors and Biosensors (2008-2012). Anal. Chem. 2013, 85, 487-508. [CrossRef]

48. Wang, X.D.; Wolfbeis, O.S. Fiber-Optic Chemical Sensors and Biosensors (2015-2019). Anal. Chem. 2020, 92, 397-430. [CrossRef] [PubMed]

49. Dakin, J.; Culshaw, B. Optical Fiber Sensors; Artech House: Boston, MA, USA, 1988; ISBN 0890069328.

50. Grattan, K.T.V.; Meggitt, B.T. Optical Fiber Sensor Technology: Fundamentals; Kluwer Academic: Boston, MA, USA, 2000; ISBN 0792378520 .

51. Koike, Y. Fundamentals of Plastic Optical Fibers; Wiley-VCH: Weinheim, Germany, 2015; ISBN 3-527-64650-7.

52. Klein, K.-F.; Mannhardt, J.; Belz, M.; Gonschior, C.; Eckhardt, H.S. Optical Fibers in Instrumental UV-Analytics. In Proceedings of the Optical Fibers and Sensors for Medical Diagnostics and Treatment Applications IX, San Jose, CA, USA, 20 February 2009; Volume 7173, p. 717302.

53. Culshaw, B. Light Interacting with Structures. In Introducing Photonics; Cambridge University Press: Cambridge, UK, 2020; pp. 72-76, ISBN $9781316609415 / 9781107155732$.

54. Fabian, M.; Lewis, E.; Newe, T.; Lochmann, S.; Mueller, I. Investigation of Ethanol and Methanol Water Mixtures in the Visible Wavelength Area Using Fibre-Optic Evanescent Field Absorption Sensors Based on a U-Shaped, a Coil-Shaped and a MeanderShaped Probe. In Proceedings of the 2008 IEEE Sensors Applications Symposium (SAS), Atlanta, GA, USA, 12-14 February 2008; pp. 79-84.

55. Li, Z.; Zhang, C.; Han, Y.; Gao, S.; Sheng, Y.; Zhang, S.; Lu, Z.; Man, B.; Jiao, Y.; Jiang, S. Evanescent Wave Absorption Sensor with Direct-Growth MoS2 Film Based on U-Bent Tapered Multimode Fiber. J. Phys. D Appl. Phys. 2017, 50, 315302. [CrossRef]

56. Khalaf, A.L.; Arasu, P.T.; Lim, H.N.; Paiman, S.; Yusof, N.A.; Mahdi, M.A.; Yaacob, M.H. Modified Plastic Optical Fiber with CNT and Graphene Oxide Nanostructured Coatings for Ethanol Liquid Sensing. Opt. Express 2017, 25, 5509-5520. [CrossRef] [PubMed]

57. MacDonald, S.; Michel, K.; LeCoq, D.; Boussard-Plédel, C.; Bureau, B. Optical Analysis of Infrared Spectra Recorded with Tapered Chalcogenide Glass Fibers. Opt. Mater. 2004, 25, 171-178. [CrossRef]

58. Fabian, M. Optical Fibre Sensor for Fuel Cell and Other Fluid Concentration Measurement. Ph.D. Thesis, University of Limerick, Limerick, Ireland, 2012.

59. Luo, J.; Ma, W.; Yao, J.; Wang, W.; Lin, Q. A Solid-Core Photonic Crystal Fiber Nanosensor. Key Eng. Mater. 2014, 609-610, 885-890. [CrossRef]

60. Girei, S.H.; Shabaneh, A.A.; Ngee-Lim, H.; Hamidon, M.N.; Mahdi, A.; Yaacob, H. Tapered Optical Fiber Coated with Graphene Based Nanomaterials for Measurement of Ethanol Concentrations in Water. Opt. Rev. 2015, 22, 385-392. [CrossRef]

61. Gao, S.S.; Qiu, H.W.; Zhang, C.; Jiang, S.Z.; Li, Z.; Liu, X.Y.; Yue, W.W.; Yang, C.; Huo, Y.Y.; Feng, D.J.; et al. Absorbance Response of a Graphene Oxide Coated U-Bent Optical Fiber Sensor for Aqueous Ethanol Detection. RSC Adv. 2016, 6, 15808-15815. [CrossRef]

62. Memon, S.F.; Lewis, E.; Ali, M.M.; Pembroke, J.T.; Chowdhry, B.S. U-Bend Evanescent Wave Plastic Optical Fibre Sensor for Minute Level Concentration Detection of Ethanol Corresponding to Biofuel Production Rate. In Proceedings of the 2017 IEEE Sensors Applications Symposium (SAS), Glassboro, NJ, USA, 13 March 2017.

63. Zhang, S.; Zhao, Y.; Zhang, C.; Jiang, S.; Yang, C.; Xiu, X.; Li, C.; Li, Z.; Zhao, X.; Man, B. In-Situ Growth of AuNPs on WS2@ U-Bent Optical Fiber for Evanescent Wave Absorption Sensor. Appl. Surf. Sci. 2018, 441, 1072-1078. [CrossRef]

64. Wang, L.; Fang, N. Applications of Fiber-Optic Interferometry Technology in Sensor Fields. In Optical Interferometry; IntechOpen: London, UK, 2017; pp. 143-163, ISBN 978-953-51-2956-1.

65. Bommareddi, R.R. Applications of Optical Interferometer Techniques for Precision Measurements of Changes in Temperature, Growth and Refractive Index of Materials. Technologies 2014, 2, 54-75. [CrossRef]

66. Khan, S.; le Calvé, S.; Newport, D.; Newport, D.A. Review of Optical Interferometry Tech-Niques for VOC Detection. Sens. Actuators A Phys. 2020, 302, 111782. [CrossRef]

67. Mudhana, G.; Park, K.S.; Ryu, S.Y.; Lee, B.H. Fiber-Optic Probe Based on a Bifunctional Lensed Photonic Crystal Fiber for Refractive Index Measurements of Liquids. IEEE Sens. J. 2011, 11, 1178-1183. [CrossRef]

68. Wu, C.; Liu, Z.; Zhang, A.P.; Guan, B.-O.; Tam, H.-Y. In-Line Open-Cavity Fabry-Pérot Interferometer Formed by C-Shaped Fiber Fortemperature-Insensitive Refractive Index Sensing. Opt. Express 2014, 22, 21757. [CrossRef] [PubMed]

69. Zhou, F.; Su, H.; Joe, H.E.; Jun, M.B.G. Temperature Insensitive Fiber Optical Refractive Index Probe with Large Dynamic Range at 1,550 Nm. Sens. Actuators A Phys. 2020, 312, 112102. [CrossRef]

70. Zhu, W.; Huang, Q.; Wang, Y.; Lewis, E.; Yang, M. Enhanced Sensitivity of Heterocore Structure Surface Plasmon Resonance Sensors Based on Local Microstructures. Opt. Eng. 2018, 57, 076105. [CrossRef]

71. Yuan, L.; Wu, H.; Wang, C.; Yu, Y.; Wang, S.; Xiao, H. Fiber Inline Michelson Interferometer Fabricated by One-Step Femtosecond Laser Micromachining for Sensing Applications. In Proceedings of the 2013 International Conference on Optical Instruments and Technology: Optical Sensors and Applications, Beijing, China, 20 December 2013; Volume 9044, p. 90441M.

72. Muri, H.I.D.I.; Bano, A.; Hjelme, D.R. First Step towards an Interferometric and Localized Surface Plasmon Fiber Optic Sensor. In Proceedings of the 25th International Conference on Optical Fiber Sensors, Jeju, Korea, 23 April 2017; Volume 10323, p. 1032323.

73. Rodriguez-Rodriguez, A.J.; May-Arrioja, D.A.; Hernandez-Romano, I.; Matías, I.R. Multimode Interference Fiber Sensors for the Monitoring of Gasoline/Ethanol Blends. In Smart Sensors, Measurement and Instrumentation; Springer International Publishing: Berlin/Heidelberg, Germany, 2017; Volume 21, pp. 329-346. 
74. Marfu'Ah; Amalia, N.R.; Hatta, A.M.; Pratama, D.Y. Multimode-Singlemode-Multimode Optical Fiber Sensor Coated with Novolac Resin for Detecting Liquid Phase Alcohol. AIP Conf Proc. 2018, 1945, 20031.

75. Michelsen, S. Optical Fiber Grating Based Sensors. Ph.D. Thesis, Technical University of Denmark, Lyngby, Denmark, 2003.

76. Quattrocchi, A.; Montanini, R.; Latino, M.; Donato, N. Development and Characterization of a Fiber Bragg Grating Ethanol Sensor for Liquids. In Proceedings of the 22nd International Workshop on ADC and DAC Modelling and Testing, Palemo, Italy, 14 September 2020; pp. 55-59.

77. Keith, J.; Puckett, S.; Pacey, G.E. Investigation of the Fundamental Behavior of Long-Period Grating Sensors. Talanta 2003, 61, 417-421. [CrossRef]

78. Raikar, U.S.; Kulkarni, V.K.; Lalasangi, A.S.; Madhav, K.; Asokan, S. Etched Fiber Bragg Grating as Ethanol Solution Sensor. Optoelectron. Adv. Mater.-Rapid Commun. 2007, 1, 149-151.

79. Possetti, G.R.C.; Muller, M.; Fabris, J.L. Refractometric Optical Fiber Sensor for Measurement of Ethanol Concentration in Ethanol-Gasoline Blend. In Proceedings of the SBMO/IEEE MTT-S International Microwave and Optoelectronics Conference, Belem, Brazil, 3-6 November 2009; pp. 616-620.

80. Terada, G.G.; Possetti, G.R.C.; Camilotti, E.; Kalinowski, H.J.; Fabris, J.L.; Muller, M. Characterization of an Encapsulated Long Period Grating Transducer Applied as a Refractometer. In Proceedings of the SBMO/IEEE MTT-S International Microwave and Optoelectronics Conference, Belem, Brazil, 3-6 November 2009; pp. 629-633.

81. Coradin, F.K.; Possetti, G.R.C.; Kamikawachi, R.C.; Muller, M.; Fabris, J.L. Etched Fiber Bragg Gratings Sensors for Water-Ethanol Mixtures: A Comparative Study. J. Microw. Optoelectron. Electromagn. Appl. 2010, 9, 131-143. [CrossRef]

82. Arasu, P.T.; Noor, A.S.M.; Shabaneh, A.A.; Girei, S.H.; Mahdi, M.A.; Lim, H.N.; Rashid, H.A.A.; Yaacob, M.H. Absorbance Properties of Gold Coated Fiber Bragg Grating Sensor for Aqueous Ethanol. Opt. Soc. Rap. Public 2014, 9, 14018. [CrossRef]

83. Bui, H.; Pham, T.B.; Nguyen, V.A.; Pham, V.D.; Do, T.C.; Nguyen, T.V.; Hoang, T.H.C.; Le, H.T.; Pham, V.H. Novel Method of Dual Fiber Bragg Gratings Integrated in Fiber Ring Laser for Biochemical Sensors. Meas. Sci. Technol. 2018, 29, 055105. [CrossRef]

84. Aristilde, S.; Cordeiro, C.M.B.; Osório, J.H. Gasoline Quality Sensor Based on Tilted Fiber Bragg Gratings. Photonics 2019,6 , 51. [CrossRef]

85. Kumar, P.; Kumar, S.; Kumar, J.; Purbia, G.S.; Prakash, O.; Dixit, S.K. Graphene-Oxide-Coated Fiber Bragg Grating Sensor for Ethanol Detection in Petrol. Meas. Sci. Technol. 2019, 31, 025109. [CrossRef]

86. Gupta, B.D.; Verma, R.K. Surface Plasmon Resonance-Based Fiber Optic Sensors: Principle, Probe Designs, and Some Applications J. Sens. 2009, 2009, 979761. [CrossRef]

87. Sharma, A.K.; Jha, R.; Gupta, B.D. Fiber-Optic Sensors Based on Surface Plasmon Resonance: A Comprehensive Review. IEEE Sens. J. 2007, 7, 1118-1129. [CrossRef]

88. Mitsushio, M.; Kamata, S. Alcohol Analysis Using a Gold-Coated Unclad Fiber Sensor System. Bunseki Kagaku 1999, 48, 757-762. [CrossRef]

89. Kurihara, K.; Ohkawa, H.; Iwasaki, Y.; Tobita, T.; Niwa, O.; Suzuki, K. A Fiber-Optic Microdevice for Surface Plasmon Resonance Sensing Using a Chemically-Etched Single-Mode Fiber. In Proceedings of the 2nd Annual International IEEE-EMBS Special Topic Conference on Microtechnologies in Medicine and Biology-Proceedings, Madison, WI, USA, 2-4 May 2002; pp. 384-385. [CrossRef]

90. Suzuki, H.; Sugimoto, M.; Matsui, Y.; Kondoh, J. Development of a Dual-Color Optical Fiber SPR Sensor. In Proceedings of the SENSORS, 2005 IEEE, Irvine, CA, USA, 30 October-3 November 2005. [CrossRef]

91. Abrahamyan, T.; Nerkararyan, K. Surface Plasmon Resonance on Vicinity of Gold-Coated Fiber Tip. Phys. Lett. A 2007, 364, 494-496. [CrossRef]

92. MITSUSHIO, M.; HIGO, M. A Gold-Deposited Surface Plasmon Resonance-Based Optical Fiber Sensor System Using Various Light-Emitting Diodes. Anal. Sci. 2011, 27, 247. [CrossRef]

93. Hlubina, P.; Kadulova, M.; Ciprian, D. Surface Plasmon Resonance Based Fiber Optic Refractive Index Sensors. In Proceedings of the 19th Polish-Slovak-Czech Optical Conference on Wave and Quantum Aspects of Contemporary Optics, Jelenia Gora, Poland, 5 December 2014; Volume 9441, p. 94411H. [CrossRef]

94. Verma, R.; Gupta, B.D. Fiber Optic Surface Plasmon Resonance Based Ethanol Sensor. In Proceedings of the Photonic Instrumentation Engineering, San Francisco, CA, USA, 2-5 February 2014; Soskind, Y.G., Olson, C., Eds.; International Society for Optics and Photonics: Bellingham, WA, USA, 2014; Volume 8992, p. 89920A.

95. Semwal, V.; Shrivastav, A.M.; Verma, R.; Gupta, B.D. Surface Plasmon Resonance Based Fiber Optic Ethanol Sensor Using Layers of Silver/Silicon/Hydrogel Entrapped with ADH/NAD. Sens. Actuators B Chem. 2016, 230, 485-492. [CrossRef]

96. Jiang, S.; Li, Z.; Zhang, C.; Gao, S.; Li, Z.; Qiu, H.; Li, C.; Yang, C.; Liu, M.; Liu, Y. A Novel U-Bent Plastic Optical Fibre Local Surface Plasmon Resonance Sensor Based on a Graphene and Silver Nanoparticle Hybrid Structure. J. Phys. D Appl. Phys. 2017, 50, 165105. [CrossRef]

97. Sharma, A.K.; Kaur, B. Chalcogenide Fiber-Optic SPR Chemical Sensor with MoS2 Monolayer, Polymer Clad, and Polythiophene Layer in NIR Using Selective Ray Launching. Opt. Fiber Technol. 2018, 43, 163-168. [CrossRef]

98. Guo, H.; Guo, J. Cavity-Coupled Conical Cross-Section Gold Nanohole Array Fiber Tip Localized Surface Plasmon Resonance Sensor. J. Nanophotonics 2020, 14, 026006. [CrossRef]

99. Orellana, G.; Gomez-Carneros, A.M.; de Dios, C.; Garcia-Martinez, A.A.; Moreno-Bondi, M.C. Reversible Fiber-Optic Fluorosensing of Lower Alcohols. Anal. Chem. 2002, 67, 2231-2238. [CrossRef] 
100. Schartner, E.P.; Tsiminis, G.; Henderson, M.R.; Warren-Smith, S.C.; Monro, T.M. Quantification of the Fluorescence Sensing Performance of Microstructured Optical Fibers Compared to Multi-Mode Fiber Tips. Opt. Express 2016, 24, 18541-18550. [CrossRef] [PubMed]

101. Saetchnikov, V.A.; Tcherniavskaia, E.A.; Schweiger, G. Development of Optical Micro Resonance Based Sensor for Detection and Identification of Microparticles and Biological Agents. Photonic Mater. Devices Appl. III 2009, 7366, 73661L. [CrossRef]

102. Berneschi, S.; Farnesi, D.; Cosi, F.; Conti, G.N.; Pelli, S.; Righini, G.C.; Soria, S. High Q Silica Microbubble Resonators Fabricated by Arc Discharge. Opt. Lett. 2011, 36, 3521. [CrossRef]

103. Yu, Z.; Liu, T.; Jiang, J.; Liu, K.; Chen, W.; Zhang, X.; Lin, X.; Liu, W. High Q Silica Microbubble Resonators Fabricated by Heating a Pressurized Glass Capillary. Adv. Sens. Syst. Appl. VI 2014, 9274, 92740L. [CrossRef]

104. Eryürek, M.; Karadag, Y.; Ghafoor, M.; Bavili, N.; Cicek, K.; Kiraz, A. Optical Sensors of Bulk Refractive Index Using Optical Fiber Resonators. Opt. Sens. 2017, 10231, 10231U. [CrossRef]

105. Nguyen, T.T.; Bae, S.O.; Kim, D.M.; Yoon, W.J.; Park, J.-W.; An, S.S.A.; Ju, H. A Regenerative Label-Free Fiber Optic Sensor Using Surface Plasmon Resonance for Clinical Diagnosis of Fibrinogen. Int. J. Nanomed. 2015, 10, 155-163. [CrossRef]

106. Xu, Y.; Xiong, M.; Yan, H. A Portable Optical Fiber Biosensor for the Detection of Zearalenone Based on the Localized Surface Plasmon Resonance. Sens. Actuators B Chem. 2021, 336, 129752. [CrossRef]

107. Elsherif, M.; Moreddu, R.; Hassan, M.U.; Yetisen, A.K.; Butt, H. Real-Time Optical Fiber Sensors Based on Light Diffusing Microlens Arrays. Lab A Chip 2019, 19, 2060-2070. [CrossRef]

108. Luna Technologies Inc. HD-SC Temperature Sensors; Luna Technologies Inc.: Roanoke, VA, USA, 2021.

109. OZ Optics Ltd. Fiber Optic Distributed Strain and Temperature Sensors (DSTS) BOTDA Module; OZ Optics Ltd.: Ottawa, ON, Canada, 2021.

110. Lu, X.; Thomas, P.J.; Hellevang, J.O. A Review of Methods for Fibre-Optic Distributed Chemical Sensing. Sensors 2019, $19,2876$. [CrossRef] [PubMed] 